\title{
Local elasto-plastic buckling of isotropic plates with cutouts under tension loading conditions
}

\author{
Marek Barski, Adam Stawiarski, Paweł J. Romanowicz, Bogdan Szybiński \\ Chair of Machine Design and Composite Structures, Cracow University of Technology \\ ul. Warszawska 24, 31-155 Cracow \\ Poland
}

Received: November 13, 2020. Revised: May 4, 2021. Accepted: May 28, 2021. Published: June 3, 2021.

\begin{abstract}
The motivation of the presented study was the observation of the existence of local loss of stability "tension buckling" in the experimental tests of composite and metallic plates with cut-outs subjected to tension. Because of this, the numerical analyses of the aluminum plate with elliptical or circular cutouts at the center and subjected to tensile load are studied in the paper. Although the whole structure is uniformly stretched, the circumferential compressive stresses in the vicinity of the cutout edge are observed. First of all, the linear buckling analysis is carried out for different sizes of the holes. Based on these results, the size of the hole is chosen, where the circumferential stress magnitude in the vicinity of the cutout is the lowest or even comparable to the yield stress of the material. The computations are made for three different values of thickness. Finally, the nonlinear buckling analysis is carried out without and with the plasticity effects included. Generally, in the case of the circular and vertically oriented elliptical cut-out, the loss of stability in the tensed plate is always observed. However, in elastic-plastic analyses, the values of the critical parameters significantly differ from the results obtained for elastic buckling. Finally, the critical geometries for further experimental tests were defined.
\end{abstract}

Keywords - finite element method, geometrical imperfections, plates with holes, post-buckling behavior tension buckling

\section{INTRODUCTION}

The buckling phenomenon of thin-walled structures is associated with the existence of an external load, which causes the compression of a whole structure or its part. When the compressive stresses reach the critical level the shape of the structure can dramatically change. From the practical point of view in most cases, it means catastrophe. A large number of classical loss of stability examples are discussed by Bushnell [1] or, in the case of laminated plates and shells, by Muc et al. [2]. However, buckling can be also possible in the case of tension [3], torsion [4], and other loads [5]. Mainly, due to the shape of a structure or different geometrical discontinuities, the stress distribution is disturbed and the compression can be also present. The local buckling under tensile loads due to the compressive stresses in thin aluminum foil with nonlinearity (cracks) was observed and numerically studied by Shahmardani et al. [3]. What is essential, such effects were also observed in the experimental tensile tests performed by the authors for composite and steel plates without cracks but with different cutouts (Fig. 1). There are presented (Fig. 1) vertical in-plane surface strains caused by vertical tensile loading. Such strains were determined with the use of the 2D Digital Image Correlation. In the first example, the composite plate (Fig. 1a) with dimensions $200 \times 200 \times 2.35 \mathrm{~mm}$ with a circular hole $\varnothing 50 \mathrm{~mm}$ at the center was made of unidirectional E-glass woven roving and Epidian 601 [6]. In the mid-side part of the sample, above and below the circular hole, there are visible compression strains. Similar effects, however, clearly on a smaller scale, were also observed in plates made of $\mathrm{S} 235 \mathrm{JR}+\mathrm{N}$ steel with circular and rectangular (Fig. 1b) cutouts in the regime of the strain hardening of the material [7]. In examples (Fig. 1c and 1d), there are presented only compressive strains - the areas in which tensile strains occurred - are marked by dark red color. The tested steel plates had a $90 \mathrm{~mm}$ width and $2 \mathrm{~mm}$ thickness. The circular and rectangular holes were equal to $\varnothing 30 \mathrm{~mm}$ and $30 \times 30 \mathrm{~mm}$, respectively. 


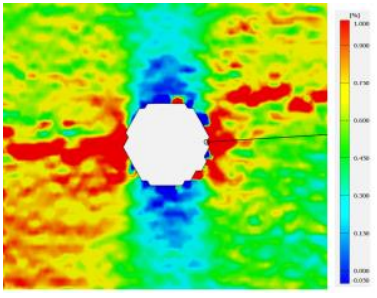

(a)

(c)

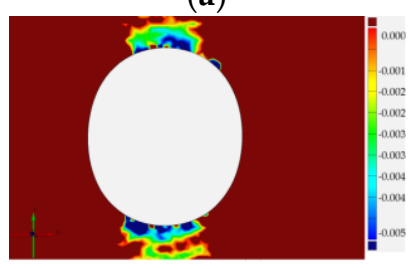

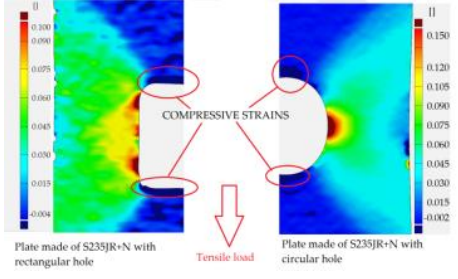

(b)

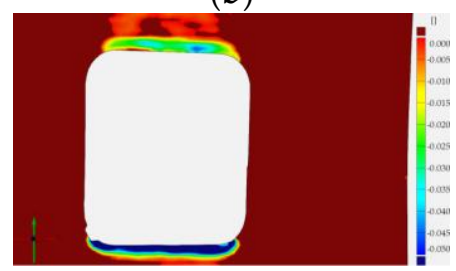

(d)
Fig. 1 Vertical surface strains caused by tensile loading (loading direction was vertical): (a) composite plate with circular hole; (b) steel plates with rectangular and circular cut-outs; (c) steel plate with circular hole (only compressive strains are presented); (d) steel plate with rectangular hole (only compressive strains are presented).

Such, above given, observations were the motivation for presented numerical analyses and further experimental issues. As another example here can be quoted paper by Yao [8], where is discussed the buckling of truncated hemisphere subjected to axial tension. A similar effect is also presented by Magnucki et al. [9], in the case of the buckling of an untypical dished head of cylindrical vessels under internal pressure. The loss of global stability in the case of the tensile load is also possible due to Poisson's effect. Friedl et al. [10] considered the relatively long rectangular isotropic plate clamped at both ends and subjected to tensile load. The applied support of the plate caused that the compressive stresses arise in the direction perpendicular to the tension. It leads to buckling, where courses of wrinkles are parallel to the long free edges of the plate. Zhang and $\mathrm{Fu}[11,12]$ introduced the new micromechanical model of the woven fabric to investigate the buckling of a fabric sheet when it is subjected to uniaxial tension. Finally, it is worth stressing here that the loss of stability by bifurcation is also possible when the compression is not present at all. Zaccaria et al. [13] investigated the bifurcation of a single degree of freedom elastic system subjected to tensile dead loading. The system consists of two rigid rods joined through a slider. Additionally, a rotational elastic spring is attached at the left hinge. The bifurcation is related to the presence of the constraint at the middle of the structure. This constraint transmits only the rotation.

The above-mentioned examples of buckling are rather connected with the shape of the structure but not with the local discontinuity of the structure. The simplest structure, where the local discontinuity may cause the buckling, is a rectangular plate under uniform tension. A crack [3] or a cutout [7] of a different shape can play a role of geometric discontinuity. In the first case, the local buckling in the vicinity of the crack edge can speed up the process of the crack length increases. Markström and Storåkers [14] present the buckling characteristics of cracked elastic plates subjected to uniaxial loads. The analysis is made with the use of the finite element method based upon linear bifurcation theory. The centrally cracked plates, as well as, three types of edge cracked members are studied. Sih and Lee [15] use the finite element method to determine and graphically display the various buckled displacement modes of a plate with a central crack. The critical buckling loads are found to decrease with increasing crack length. Shaw and Huang [16] also use the finite element method. The applied approach is based on Von Karman's linearized theory for buckling of plates subjected to a pre-buckling state of plane stress. Moreover, several singular elements based on the Willian series are used. In this study, the effect of crack length, the effect of boundary condition, the effect of Poisson's ratio, and the effect of biaxial force on critical loads are studied. The effect of initial imperfection is also considered. Riks et al. [17] propose the procedure based on the finite element method for the analysis of buckling and post-buckling behavior of centrally localized cracks in the case of stretched plates. The obtained results show that the loss of stability can cause a considerable amplification of stress intensity around the crack tip. This phenomenon increases with the length of the crack. The influence of the local crack buckling on the energy release rate is studied by Barut et al. [18] in the case of a thin, rectangular, composite plate. The analysis is carried out with the use of the finite element method in a nonlinear range. The obtained results show that the local buckling load of the cracked plate increases as the crack orientation changes from a transverse crack to a longitudinal crack aligned with the direction of the applied tension load. Moreover, the local crack buckling increases the energy release rate thus resulting in a reduction in residual strength. Guz and Dyshel [19] and Dyshel [20] study the buckling and cracking of thin aluminum panels with an edge crack in tension. The impact of end conditions on the loss of stability resistance is investigated. Next, Guz and Dyshel [21] investigate the two-layered plate, which consists of steel and aluminum alloy AMg6M with a central crack. The authors introduce the simple closed analytical formula describing the value of the critical tension load. This formula is based on the rule of mixtures. A good agreement between theoretical and experimental results is obtained. The loss of stability is not always observed. However, if this phenomenon occurs, it will speed up the crack length increasing. Brighenti [22-24] performs the numerical buckling analysis (eigenvalue problem as well as nonlinear analysis with the contact between the edge of the crack taken into account) of the isotropic plate with crack with the use of finite element method. The analysis reveals that in the case of compression, the loss of stability has a global character independently of the type of support of the structure. However, in the case of tension, this phenomenon has a local character. Moreover, for a longer crack, the value of the critical tension load decreases. The most dangerous cracks are oriented in the perpendicular direction with respect to the direction of tension. The author studies also the 
influence of Poisson's effect. This effect is not significant. Next, the simple analytical formula describing the value of the critical load is also introduced. Finally, plasticity is also taken into account. Rad and Panahandeh-Shahraki $[25,26]$ perform a similar analysis for the plate made of functionally graded material (FGM) with a crack. The obtained results generally agree with those, which are described above. The experimental analysis of the stretched plate with crack is presented by Seif and Kabir [27]. The authors investigated the influence of the symmetric and anti-symmetric form of buckling in the vicinity of the crack on the fracture and fatigue behavior. Results show that the buckling can reduce the fracture capacity and the fatigue life by $35 \%$ and $59 \%$ respectively. The anti-symmetric buckling has a greater influence on the fracture capacity loss due to the mix mode of I-III but it has an opposite effect on the fatigue crack growth due to the sliding crack closure. The obtained experimental results are also compared with the numerical ones.

To sum up, it is worth stressing that the existence of the crack in the stretched plates causes that the local buckling in the vicinity of the crack edges is possible. The lowest buckling load is obtained for crack orientation, which is perpendicular to the direction of tension. The local loss of stability, especially anti-symmetric mode, speeds up the crack length increasing. In the case of cutouts of a different shape, similar effects should be observed. For the first time, the problem of the loss of stability at holes under a global tensile load was described by Cherepanov [28] in 1963. Since then only a few works deal with this problem. Here can be quoted works by Backer [29], Datta and Carlson [30], or Datta [31] published at the beginning of the $70 \mathrm{~s}$ of the last century. Next, Larsson [32] in 1989 computes the buckling load for pierced linear elastic rectangular composite plates having centrally located circular holes with the aid of the finite element method. The obtained predictions are verified experimentally. Moreover, buckling modes are also examined, in particular with respect to symmetries and anti-symmetries. Shimizu et al. [33] perform the finite element analysis on the elastic buckling of plates, each of which has a hole and is subjected to tensile loading. In this paper, stress distributions and buckling behaviors are studied. Aspect ratios, shapes of holes, and so on, are adopted as parameters. Through the analysis, variations of buckling coefficients and buckling modes against aspect ratios are obtained. The effects of the hole shapes on the buckling strength are also discussed. In the next paper by Gilabert et al. [34] the effect of imperfect boundary conditions and the finite size of the plate are analyzed by comparing a numerical finite element computation and some experiments carried out in the simplest case of a circular hole. Experiments with cracks clearly show the distortion of the buckling pattern as a function of the crack orientation with respect to the applied uniaxial tensile stress.

The influence of the different shapes of the holes on critical buckling load in the case of a square isotropic plate is studied by Prabhakara and Datta [35]. The circular and elliptical holes and rectangular slots with rounded ends are taken into consideration. The finite element method is applied. The value of critical buckling load is obtained as a result of eigenvalue analysis. The tension buckling is also investigated in the case of doubly curved composite panels subjected to partial edge loading. Kumar et al. [36], [37] use the finite element method to solve the eigenvalue problem describing the value of critical load as well as the dynamic behavior of the structure. The computations are carried out for composite panels with and without centrally placed circular holes. The critical buckling load increases with the increase of the curvature of the panel. For certain panels, the buckling behavior is similar to flat plates, depending on the edge conditions and aspect ratio of the panel. The impact of the length of the isotropic plate, the size, and the shape of the holes on the value of buckling load are investigated by Shimizu [38]. The width of the plate is assumed to be fixed. The finite element method is applied. To obtain the values of the buckling load, the eigenvalue analysis is carried out. Depending on the aspect ratio of the plate the symmetric or anti-symmetric buckling mode is obtained. The lowest value of buckling load is obtained for the rectangular cutouts. The different methods of edge load application are also analyzed. However, for the relatively long plates, the influence of it is not significant. The nonlinear analysis is also performed with the plasticity taken into account. The influence of geometrical imperfections is studied. The conclusion is that the impact of the imperfections is similar to the case of compressed plates. Similar work is presented by Kremer and Schürmann [39], but in this case, the plates are made of composite materials. The authors use as before the finite element method and the eigenvalue problem is solved to find the value of buckling load. The nonlinear analysis is also carried out. One of the conclusions is that for thin plates, with thickness $\mathrm{t} \approx 0.01 \mathrm{~mm}$, the value of the buckling load is lower in comparison with load, which causes damage of the structure. It makes possible the experimental observation of the tension buckling phenomenon in the reality. As an imperfection, the first buckling mode is superimposed to the plate. Finally, the results of analytical and numerical analysis of the tension buckling of laminated sheets with circular and elliptical holes are discussed by Muc [40]. The performed studies reveal the significant impact of stress concentration effect on buckling modes and loads, particularly taking into consideration variations of the Young's and Kirchoff's modulus ratios. The problem of optimal design is also discussed. Both continuous and discrete fiber orientations are considered.

The main motivation of this work is to estimate the "optimal" conditions (thickness of the plate, the shape, and size of the hole), for which the loss of stability in the case of the isotropic plate with cut-out subjected to tension is the most probable. In order to perform this study, the finite element method is used. This method is very universal and the usage of this method makes it possible to perform the analysis also in the nonlinear range, mainly due to the exceeding the yield stress of the material. Moreover, practically there is no 
limitation on the shape of the cut-out. Thus, it seems that the choice of the FEM method is the most suitable. What more, the present study should be treated as a preliminary analysis before performing the experimental tests. We look for the structure, for which the loss of stability in the neighborhood of the cut-out causes such a magnitude of the normal deflection, which can be observed with the use of the DIC system.

\section{MATERIALS AND METHODS}

The investigated structure with a hole is shown in Fig. 2. The plate is made of aluminum alloy EN AW 1050A H14. The mechanical properties of the material are as follows: the Young modulus $\mathrm{E}=69$ [GPa], the Kirchhoff module $\mathrm{G}=25.9[\mathrm{GPa}]$, the Poisson's ratio $\mathrm{v}=0.33$ and density $\rho=2.79\left[\mathrm{~g} / \mathrm{cm}^{3}\right]$. For the sheets, where the thickness $t$ is between $0.5[\mathrm{~mm}]$ to $1.5[\mathrm{~mm}]$, the yield stress is equal $\mathrm{R}_{\mathrm{p} 02}=85[\mathrm{MPa}]$, the tensile strength $\mathrm{R}_{\mathrm{m}}=105-145$ [MPa], and the minimal elongation $\mathrm{A}=3[\%]$. The plate is a square with an edge length equal to $\mathrm{L}=200 \mathrm{~mm}$. The circular or elliptic cutout is localized in the geometrical center of the plate. The longer semi-axis can be oriented in the horizontal or vertical direction. The size of the hole is variable. The analysis is carried out for three values of the thickness: $\mathrm{t}=0.5,1.0$, and $1.5 \mathrm{~mm}$. Since the performed numerical simulation mimics the real experiment with the use of the tension machine, one edge of the plate is fixed and the second one can move in the direction of the applied load. Taking under consideration the orientation of the global coordinate system, the assumed boundary conditions are shown in Fig. 2, where UX, UY, UZ, ROTZ are the translational and rotational degrees of freedom, respectively.

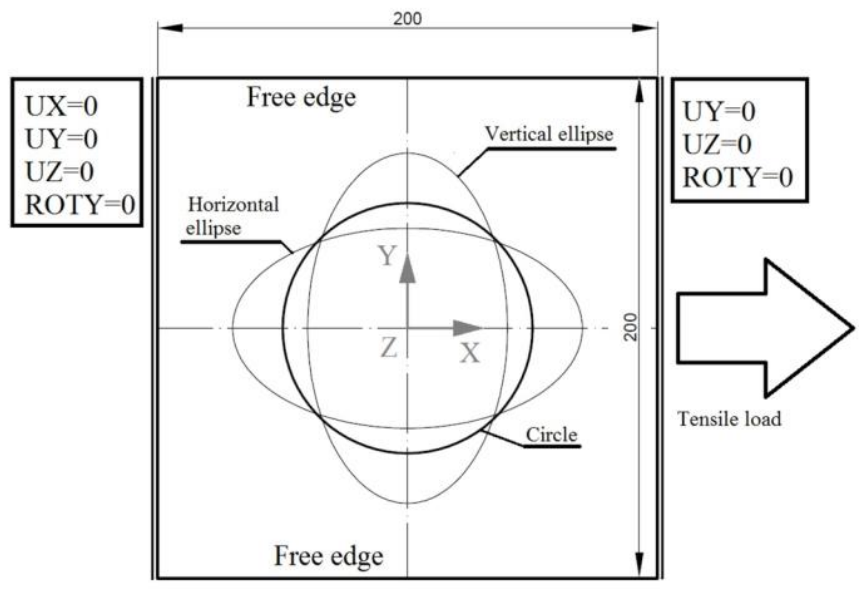

Fig. 2 The isotropic square plate with circular and elliptical cutouts.

All computations are performed with the use of ANSYS software. With this system, the whole steps of the full buckling analysis can be performed, namely linear buckling (eigenvalue analysis), nonlinear buckling analysis (post-buckling analysis) with the large deflection and material nonlinearity taken into account, and sensitivity analysis on geometrical imperfections. Moreover, the ANSYS system is also implemented the arclength metod, which enables performing the in the case when the post-buckling behavior of the studied structure is unstable. Due to the fact that the load is applied only on the one edge whereas the second one is clamped, the final shape of the structure after the loss of stability may not be symmetric concerning the $\mathrm{Y}$-axis. Among the available in the ANSYS system FEM models, the shell model seems to be the most appropriate. The elements of the shell model possess all necessary degrees of freedom in each node, which makes it possible to perform the full buckling analysis in the linear and non-linear range. Therefore the whole structure is modeled as a shell structure. The standard higher-order shell elements SHELL281 are applied. Such finite elements have six degrees of freedom at each node, namely: three translational UX, UY, UZ, and three rotational ROTX, ROTY, ROTZ. These elements are formulated according to the first-order shear deformation theory. The elements of triangular shape are used. Moreover, it is assumed that the approximate element size in the vicinity of the hole is smaller in comparison with the size of the elements, which are located in the remaining part of the structure. For the sake of simplicity, it is also assumed that the size of the elements, which are located far from the hole edge, have a fixed size $1=5.0 \mathrm{~mm}$. On the other hand, the size of the elements, which are located in the vicinity of the hole, is estimated based on the result of the convergence test of the numerical solution. This test is carried out for the structure, where the thickness is equal to $\mathrm{t}=1.0 \mathrm{~mm}$ and the cutout has a circular shape with a diameter $d=100 \mathrm{~mm}$. The eigenvalue problem is solved and the value of the external buckling load (pressure $p_{c r}$ ) is tested. The obtained results are shown in Table 1.

Table 1 The results of the convergence test of the finite element solution.

\begin{tabular}{|c|c|c|}
\hline $\begin{array}{c}\text { Element size } \\
{[\mathbf{m m}]}\end{array}$ & $\begin{array}{c}\text { Buckling tensile pressure } \\
\boldsymbol{p}_{\boldsymbol{c r}}[\mathbf{M P a}]\end{array}$ & $\begin{array}{c}\text { Tensile force } \\
\boldsymbol{F}_{\boldsymbol{c r}}[\mathbf{k N}]\end{array}$ \\
\hline 5.0 & 56.895 & 11.379 \\
\hline 4.0 & 56.754 & 11.351 \\
\hline 3.0 & 56.635 & 11.327 \\
\hline 2.0 & 56.581 & 11.316 \\
\hline 1.0 & 56.536 & 11.307 \\
\hline 0.5 & 56.532 & 11.306 \\
\hline
\end{tabular}

As it can be observed in Table 1, the value of the critical buckling pressure (tensile force) varies not significantly. Therefore for further computations, the element size in the vicinity of the cutout edge can be chosen to be equal to $1=1.0 \mathrm{~mm}$. The use of the second-order shell elements SHELL281 guarantees the good accuracy of the solution. As it can be observed (Table 1) starting from element size $1=1.0$ we have two digits after the decimal point identical in the case of the value of critical pressure. We decided that this result is enough for further analysis and ensures the appropriate accuracy. Besides, we have to assume that if one parameter (value of critical pressure) indicates a good convergence thus it means that other parameters, for example, the value of the normal deflection, measured at point A, also indicate a similar tendency. The part of the finite element model of the studied plate is depicted in Fig. 3. 


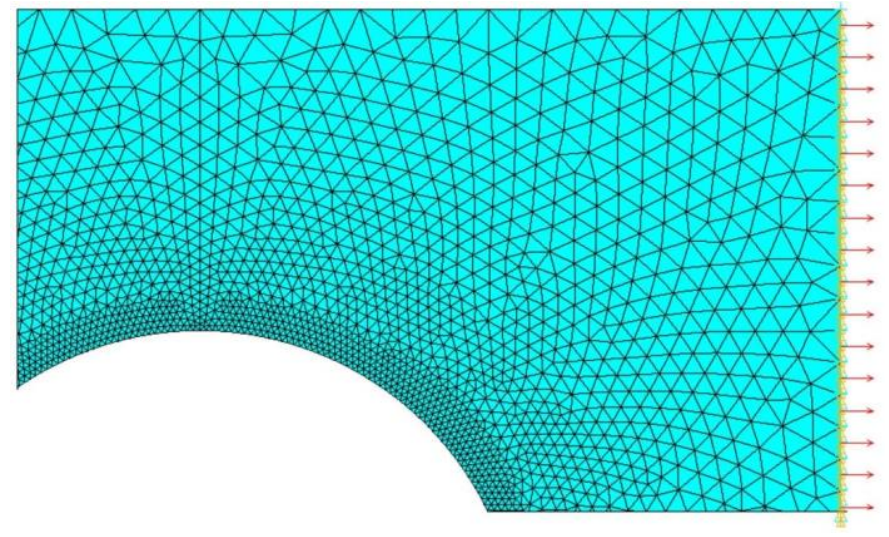

Fig. 3 The part of the finite element model of the investigated plate with a circular hole.

\section{RESULTS}

\section{I.1 Linear buckling - parametric analysis}

As it is mentioned above, the parametric analysis is carried out in order to estimate the size of the hole, for which the critical circumferential stress component (in the vicinity of the hole) is comparable with the yield stress of the plate material. In other words, for relatively small cutouts the critical circumferential stresses are very high. In reality, such stresses cause the failure of the structure before the buckling phenomenon could be observed. Thus the present study is performed for the structures which differ from each other by the size of holes. In the case of the circular hole the calculations are made for the following diameters, namely: $\mathrm{d}=25,50,75,100$, and $125 \mathrm{~mm}$. In the case of the vertical ellipse, the length of the longer semi-axis is equal to $a=4 \mathrm{~d} / 3$ and the length of the shorter semi-axis $b=3 d / 4$, where $d$ is the diameter of the corresponding circular hole. In the case of the horizontal ellipse, the lengths of semi-axes are respectively $a=3 d / 4$ and $b=4 d / 3$. It is worth pointing out that the areas of the corresponding circular and elliptic cutouts are the same. The orientation of the cutouts with respect to the load direction is depicted in Fig. 4.

The calculations are performed for two load cases. In the first case, the load is controlled by the pressure $p$, which is applied on the right edge of the plate and the critical multiplier of this loading is looked for. In the second case, the load is controlled by the magnitude of the uniform horizontal displacement UX. The vector of the displacement UX is directed identically as it is shown in Fig. 2.

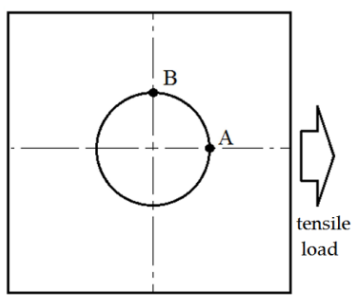

(a)

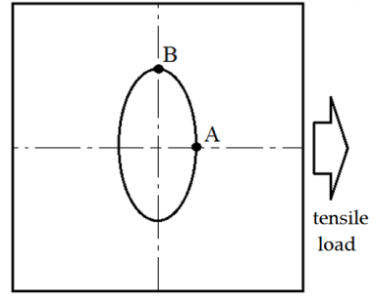

(b)

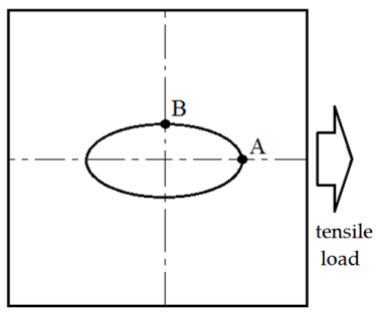

(c)

Fig. 4 Studied structures with: (a) circular hole; (b) vertically oriented elliptic cutout; (c) horizontally oriented elliptic cutout. Location of the measurement points $\mathrm{A}$ and $\mathrm{B}$.

\section{I.1.1 Loading controlled by pressure p}

The obtained results for the linear buckling approach with loading controlled by pressure are presented in Figure 5. As it can be observed in Fig. 5a, for the relatively small cutouts the magnitude of the external tension pressure $p_{c r}$ is very high. Moreover, the shape of the hole has a significant impact on these parameters. The highest value is obtained in the case of the horizontally oriented elliptical cutout and the thickness of the plate $\mathrm{t}=1.5 \mathrm{~mm}$. On the other hand, for the plates of thickness $\mathrm{t}=1.0 \mathrm{~mm}$ and $\mathrm{t}=0.5 \mathrm{~mm}$ with a circular hole and for all plates with vertically oriented elliptical cutouts the critical buckling pressures $p_{c r}$ are comparable and relatively small. The next plot, Fig. 5b, which shows the relationship between critical axial force $F_{c r}$ and a diameter $d$ of the circular hole is very similar. In Fig. $5 \mathrm{c}$ and Fig. $5 \mathrm{~d}$ there are also depicted the extreme values of a circumferential component of stresses in the membrane state, which are measured in two characteristic points located on the cutout edge (compression $\sigma_{\theta}{ }^{\mathrm{A}}$, point $\mathrm{A}$ and tension $\sigma_{\theta}{ }^{\mathrm{B}}$, point $\mathrm{B}$ ). The locations of these points are depicted in Fig. 4. Such stresses arise when the investigated structure is subjected to the external load, which is equal to the critical buckling pressure $p_{c r}$. The magnitude of these stresses significantly depends on the cutout size. Generally, for smaller cut-outs, they are higher. Moreover, in analyzed cases, the minimum is observed for the circular hole with a diameter $d$ equal to about $\mathrm{d}=100 \mathrm{~mm}$. In the case of circular and vertically oriented elliptical holes and thickness $\mathrm{t}=0.5 \mathrm{~mm}$ these stresses are comparable with the yield stress of the applied material. Thus, in these cases, it should be possible to observe the buckling phenomenon even in the elastic range. In the other cases, the stresses are high and the loss of stability is possible only when the plasticity effects are included. The first buckling modes of the studied plates are presented in Fig. 6. Additionally, the distributions of the circumferential 
component of the stresses with their extreme values are shown in Fig. 7.

(a)

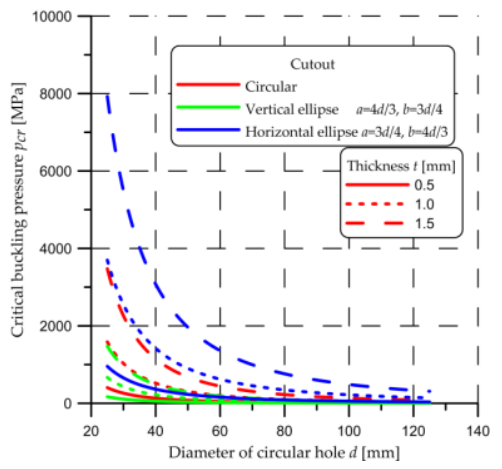

(b)

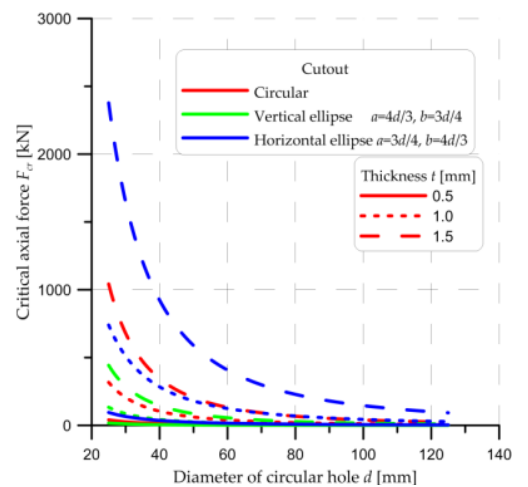

(c)

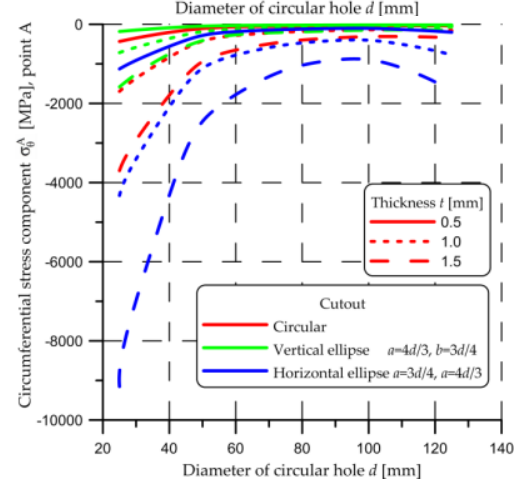

(d)

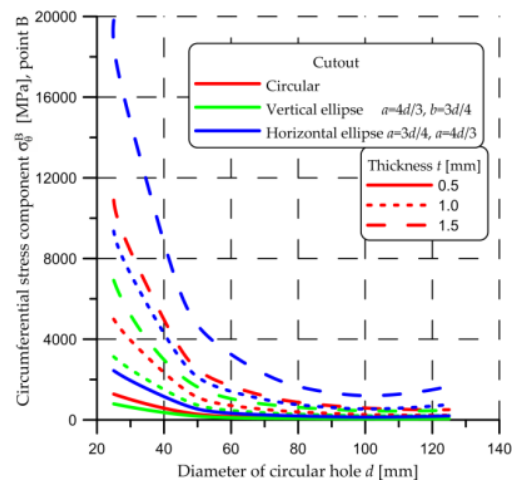

Fig. 5 Relationships between characteristic size of cutout $d$ and: (a) critical buckling pressure $p_{c r}$; (b) critical axial force $F_{c r} ;$; (c) circumferential stress component $\sigma_{\theta}{ }^{\mathrm{A}}$ at point $\mathrm{A}$; (d) circumferential stress component $\sigma_{\theta}{ }^{\mathrm{B}}$ at point $\mathrm{B}$.

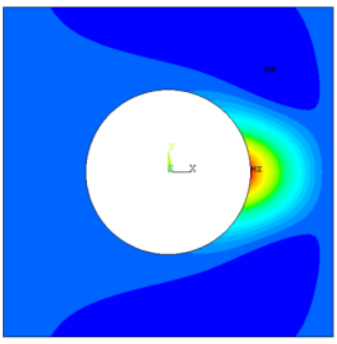

(a)

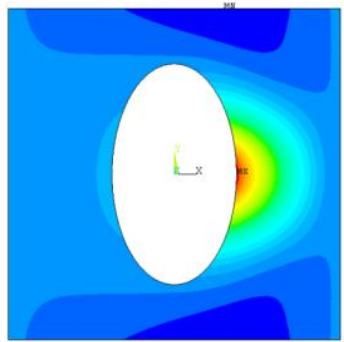

(b)

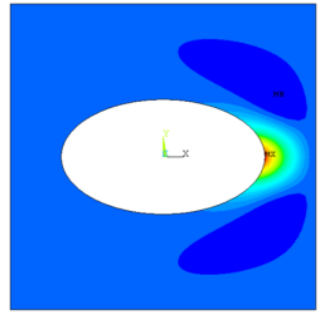

(c)

Fig. 6 First buckling modes of investigated plates, thickness $\mathrm{t}=1.0$ $\mathrm{mm}$. Load controlled by pressure pcr: (a) circular hole, $p_{c r}=56.536$ [MPa]; (b) vertically oriented elliptic cutout, $p_{c r}=24.496$ [MPa]; (c) horizontally oriented elliptic cutout, $p_{c r}=176.231[\mathrm{MPa}]$.

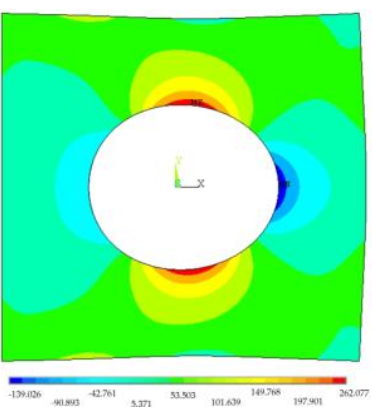

$\sigma_{\theta}{ }^{\mathrm{A}}=-139.026[\mathrm{MPa}]$ $\sigma_{\theta}{ }^{\mathrm{B}}=262.077[\mathrm{MPa}]$

(a)

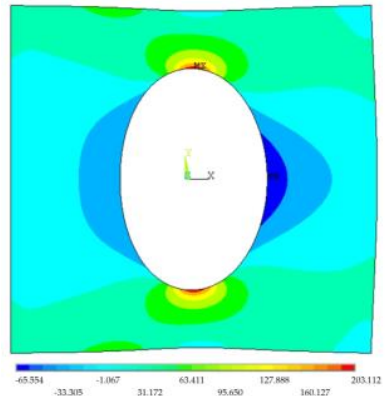

$\sigma_{\theta}{ }^{\mathrm{A}}=-65.544[\mathrm{MPa}]$ $\sigma_{\theta}{ }^{\mathrm{B}}=203.112[\mathrm{MPa}$

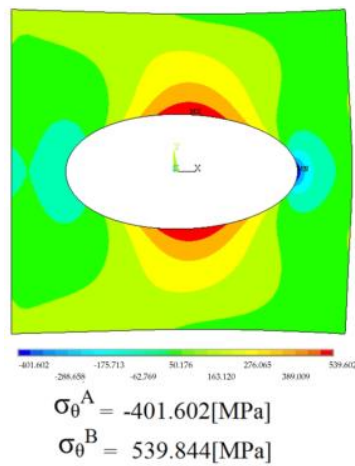

(c)

Fig. 7 The contours of the circumferential stress component, thickness $\mathrm{t}=1.0 \mathrm{~mm}$ : (a) circular hole; (b) vertically oriented elliptic cutout; (c) horizontally oriented elliptic cutout. 


\section{I.1.2 Loading controlled by horizontal displacement UX}

The obtained results, when the tension load is controlled by the uniform horizontal displacement UX, are presented in Figure 8a. Generally, the characters of the shown plots are similar to those, which are discussed for the case with loading controlled by pressure (Figure 5). As before the highest value of the critical horizontal displacement UX is observed for the relatively small size of the cutouts. However, in the case of the horizontally oriented ellipse, the clear minimum is observed. Moreover, for the plates with the largest studied cut-outs, the buckling phenomenon is not observed. This fact can be explained by the influence of the boundary conditions on the stiffness of the plate in the area, where the buckling is expected. The relationship between the corresponding to the critical displacement UX axial force $F_{c r}$ and the characteristic size of the cutout $d$ is depicted in Fig. 8b. The value of the critical axial force $F_{c r}$ decreases with increasing the parameter $d$. It can be said that in reality, the loss of stability is possible only for relatively large cutouts (vertically oriented elliptical or circular cutouts) and for the plate thickness $\mathrm{t}=0.5 \mathrm{~mm}$ or $\mathrm{t}=1.0 \mathrm{~mm}$. In the case of horizontally oriented elliptical cutouts, the obtained values of axial force $F_{c r}$ are enormously high. It causes that the magnitude of circumferential components of stresses $\sigma_{\theta}{ }^{\mathrm{A}}$ and $\sigma_{\theta}{ }^{\mathrm{B}}$ are also very high, which can be observed in Fig. 8c and Fig. 8d. The first buckling modes of the studied plates are shown in Fig. 9. On the contrary to the modes presented in Fig. 6, now the obtained shapes are symmetric with respect to the axis, which goes through the geometrical center of the structure. A similar effect is observed in the case of the distributions of the circumferential component of the stresses (Fig. 10). Moreover, now the presented extreme values of the stresses $\sigma_{\theta}{ }^{\mathrm{A}}$ and $\sigma_{\theta}{ }^{\mathrm{B}}$ are generally much higher in comparison with those which are shown in Fig.7.

To sum up, it should be stressed that the way how the tension load is realized (pressure or displacement controlled) has a significant effect on the final results. Generally, in the case of the buckling, where the applied load is controlled by the displacement, the values of the critical parameters (axial force, stresses at point A and B) are higher in comparison with those, which are obtained when the load is controlled by the edge pressure. However in reality the load applied directly through the pressure or force is very difficult to implement. Especially in the case of the tension load applied to the edge of the plate. Thus it seems that the model, where the load controlled by the displacement, is more corresponding with reality. Moreover, for relatively large cutouts the magnitude of the circumferential components of stress are comparable with the yield stress of the plate material. However, the stresses $\sigma_{\theta}{ }^{\mathrm{B}}$ are much higher. Therefore it seems that the loss of stability can be observed only for the relatively large cutouts when the plasticity effect is included. Taking under consideration the presented above results, it is assumed that further nonlinear analysis will be performed for the plates with a circular hole with diameter $\mathrm{d}=100 \mathrm{~mm}$ and for corresponding vertically $(a=133.33 \mathrm{~mm}, \quad b=75 \mathrm{~mm})$ and horizontally $(a=75 \mathrm{~mm}$, $b=133.33 \mathrm{~mm}$ ) oriented elliptic cutouts.

(a)

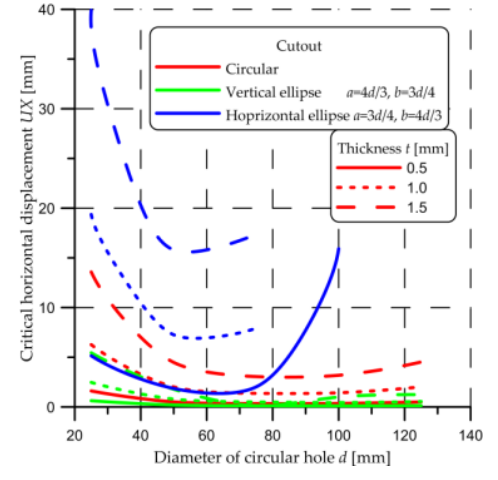

(b)

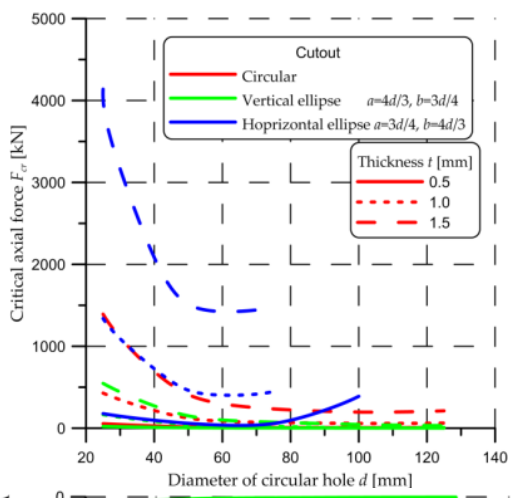

(c)

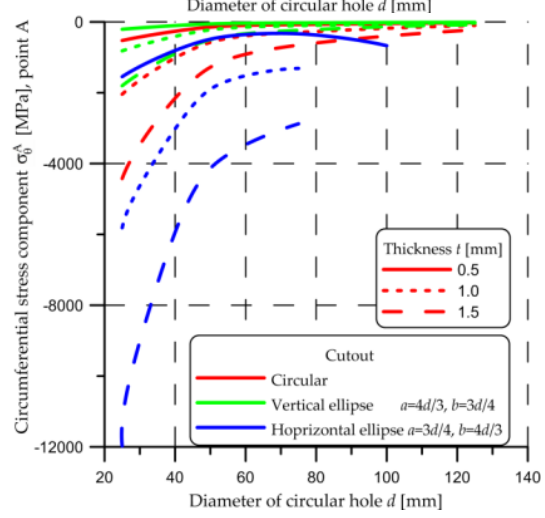

(d)

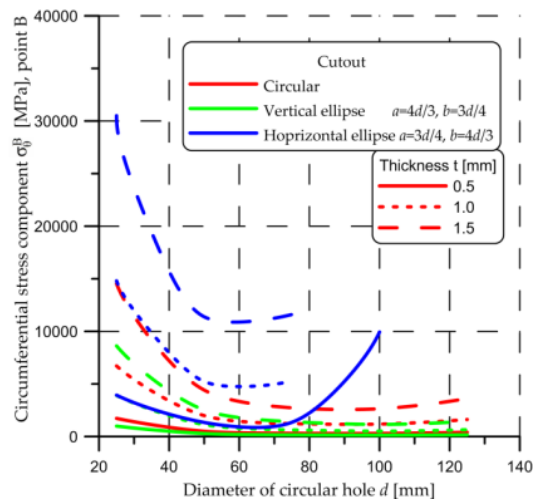

Fig. 8 Relationships between characteristic size of cutout $d$ and: (a) critical horizontal displacement UX; (b) critical axial force $F_{c r}$; (c) circumferential stress component $\sigma_{\theta}{ }^{\mathrm{A}}$ at point $\mathrm{A}$; (d) circumferential stress component $\sigma_{\theta}{ }^{\mathrm{B}}$ at point $\mathrm{B}$. 


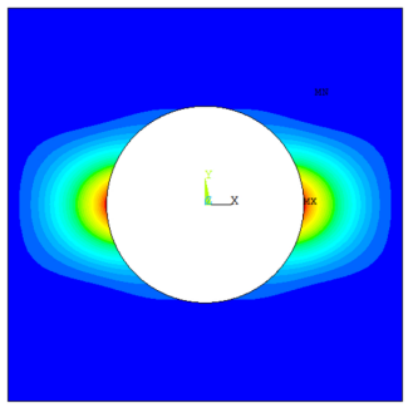

(a)

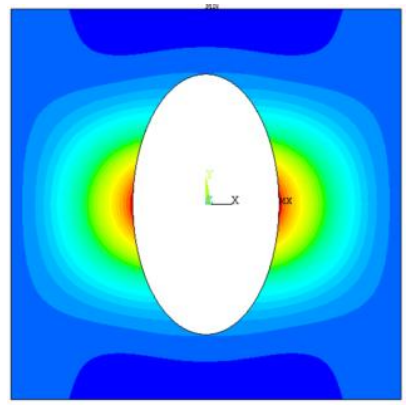

(b)
Fig. 9 First buckling modes of investigated plates, thickness $\mathrm{t}=1.0 \mathrm{~mm}$. Load controlled by the edge displacement: (a) circular hole, UX=1.427 mm; (b) vertically oriented elliptic cutout, UX $=0.445 \mathrm{~mm}$.

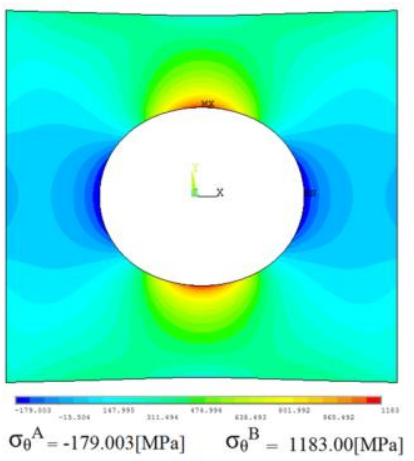

(a)

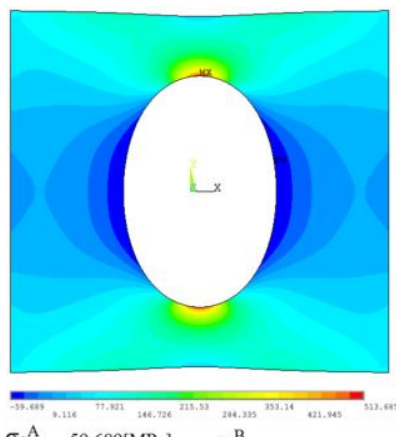

(b)
Fig. 10 The contours of the circumferential stress component, thickness $\mathrm{t}=1.0 \mathrm{~mm}$ : (a) circular hole; (b) vertically oriented elliptic cutout.

Finally, Table 2 and Table 3 collected the obtained critical parameters for the linear buckling analysis when the load is controlled by the pressure or displacement, respectively. These results relate to a plate with a hole with a characteristic dimension of $\mathrm{d}=100 \mathrm{~mm}$ and different thickness $t$. In Table 2 in the second and third column, the values of critical pressures and the corresponding value of critical axial forces are presented respectively. Moreover, in the two last columns, there are shown the values of the circumferential stress components, which are measured in points $\mathrm{A}$ and $\mathrm{B}$. The location of these points is shown in Fig. 4.

It is worth stressing here that in the case of the horizontally oriented elliptic cut-out when the load is controlled by displacement UX, the loss of stability is not observed for plates of the thicknesses $\mathrm{t}=1.0 \mathrm{~mm}$ and $\mathrm{t}=1.5 \mathrm{~mm}$. However, for plates of thickness $\mathrm{t}=0.5 \mathrm{~mm}$ the value of critical displacement UX is extremely large. Such a displacement value seems to be rather unreachable in reality. As is mentioned above, the presented in these tables values of the critical axial force as well as the magnitude of the stresses $\sigma_{\theta}{ }^{\mathrm{A}}$ and $\sigma_{\theta}{ }^{\mathrm{B}}$ are significantly higher when the load is controlled by the horizontal displacement UX. Especially, it is visible in the case of the circumferential component of stress $\sigma_{\theta}{ }^{\mathrm{B}}$. Taking under consideration the value of the yield stress $\left(R_{p 02}=85\right.$ $\mathrm{MPa}$ ), the loss of stability in the elastic range is possible only in the case of the plate with thickness $\mathrm{t}=0.5 \mathrm{~mm}$ and with circular and vertically oriented elliptic cutout. It should be assumed that in any other cases the plasticity effects are active.

Table 2. Linear buckling analysis. The tension load controlled by edge pressure $p_{c r}$.

\begin{tabular}{|c|c|c|c|c|}
\hline $\begin{array}{c}\text { Thickness } \\
\mathbf{t}[\mathbf{m m}]\end{array}$ & $\begin{array}{c}\boldsymbol{p}_{\boldsymbol{c r}} \\
{[\mathbf{M P a}]}\end{array}$ & $\begin{array}{c}\text { Axial force } \\
\boldsymbol{F}[\mathbf{k N}]\end{array}$ & $\begin{array}{c}\boldsymbol{\sigma}^{\mathbf{A}} \\
{[\mathbf{M P a}]}\end{array}$ & $\begin{array}{c}\boldsymbol{\sigma}_{\boldsymbol{\theta}}^{\mathbf{B}} \\
{[\mathbf{M P a}]}\end{array}$ \\
\hline \multicolumn{5}{|c|}{ ircular hole $d=100[\mathrm{~mm}]$} \\
\hline 0.5 & 14.218 & 1.422 & -34.964 & 65.909 \\
\hline 1.0 & 56.536 & 11.307 & -139.026 & 262.077 \\
\hline 1.5 & 126.432 & 37.930 & -310.913 & 586.073 \\
\hline Vertically oriented elliptical cutout $a=133.33[\mathrm{~mm}], b=75[\mathrm{~mm}]$ \\
\hline 0.5 & 6.149 & 0.615 & -16.453 & 50.990 \\
\hline 1.0 & 24.496 & 4.899 & -65.544 & 203.112 \\
\hline 1.5 & 54.890 & 16.467 & -146.868 & 455.097 \\
\hline Horizontally oriented elliptical cutout $a=75[\mathrm{~mm}], b=133.33[\mathrm{~mm}]$ \\
\hline 0.5 & 44.565 & 4.456 & -101.558 & 136.515 \\
\hline 1.0 & 176.231 & 35.246 & -401.606 & 539.846 \\
\hline 1.5 & 391.864 & 117.559 & -893.000 & 1200.00 \\
\hline
\end{tabular}

Table 3. Linear buckling analysis. The tension load controlled by horizontal displacement UX.

\begin{tabular}{|c|c|c|c|c|}
\hline $\begin{array}{c}\text { Thickness } \\
\mathbf{t}[\mathbf{m m}]\end{array}$ & $\begin{array}{c}\boldsymbol{U} \boldsymbol{A} \\
{[\mathbf{m m}]^{*}}\end{array}$ & $\begin{array}{c}\text { Axial force } \\
\boldsymbol{F}[\mathbf{k N}]\end{array}$ & $\begin{array}{c}\boldsymbol{\sigma}^{{ }^{\mathbf{A}}} \\
{[\mathbf{M P a}]}\end{array}$ & $\begin{array}{c}\boldsymbol{\sigma}^{{ }^{\mathbf{B}}} \\
{[\mathbf{M P a}]}\end{array}$ \\
\hline \multicolumn{5}{|c|}{ ircular hole $d=100[\mathrm{~mm}]$} \\
\hline 0.5 & 0.359 & 7.396 & -45.063 & 297.944 \\
\hline 1.0 & 1.427 & 58.758 & -179.003 & 1183.491 \\
\hline 1.5 & 3.187 & 196.839 & -399.798 & 2643.187 \\
\hline Vertically oriented elliptical cutout $a=133.33[\mathrm{~mm}], b=75[\mathrm{~mm}]$ \\
\hline 0.5 & 0.112 & 1.686 & -14.851 & 128.952 \\
\hline 1.0 & 0.445 & 13.429 & -59.163 & 513.685 \\
\hline 1.5 & 0.997 & 45.134 & -132.566 & 1151.000 \\
\hline Horizontally oriented elliptical cutout $a=75[\mathrm{~mm}], b=133.33[\mathrm{~mm}]$ \\
\hline 0.5 & 15.920 & 388.932 & -671.089 & 9939.780 \\
\hline 1.0 & \multicolumn{5}{|c|}{ The loss of stability is not observed } \\
\hline 1.5 & \multicolumn{5}{|c|}{} \\
\hline
\end{tabular}

*UX - the critical value of horizontal displacement for which the loss of stability occurs.

Additionally, it is worth comparing the obtained numerical results with the semi-empirical ones, which are available in the other papers. The approximate analytical relationship describing the value of the critical tension load can be found in work by Shimizu [37]. In this paper the application of the Euler's beam formula with a correction coefficient $k$ is proposed, namely:

$$
p_{c r}=k \frac{\pi^{2} E}{12\left(1-v^{2}\right)}\left(\frac{t}{L_{X}}\right)^{2}
$$


The correction coefficient $\mathrm{k}$ is derived numerically. It is a function of the aspect ratio $L_{x} / L_{y}$, where the $L_{x}$ and $L_{y}$ are the lengths of the plate edges and the type of the cutout (i.e circular, square, etc.). In the case of the plate where the aspect ratio is equal to $L_{x} / L_{y}=1$ and circular hole, the correction coefficient is equal to about $\mathrm{k}=20.1$. However, in this work, it is assumed the constant diameter of the circular hole, namely $\mathrm{d}=400 \mathrm{~mm}$, and constant length of the $L_{x}=800 \mathrm{~mm}$ for all studied structures, which differs from each other only by the aspect ratio $L_{x} / L_{y}$. The aspect ratio $d / L_{x}$ in the present work is the same as in the paper by Shimizu [33]. In the mentioned work the information about the elliptical cutouts is not available. Thus the estimation can be done only for the plates with circular holes. Next, Kremer Schürmann [34] propose the empirical formula for the buckling stress of isotropic plates:

$$
p_{c r}=3.55 E\left(\frac{2 t}{d}\right)^{2}
$$

In both cases, $t$ and $d$ mean the thickness of the plate and the diameter of the circular hole, respectively.

In Table 4 there are compared the values of critical buckling pressure $p_{c r}$ obtained with the use of the above formulas and the results of numerical analysis. As it can be observed, the values obtained with the use of formula (1) are significantly underestimated in comparison with those which are obtained from the numerical analysis. This fact can be caused by the effect of boundary conditions. On the other hand, the critical buckling pressure $p_{c r}$ computed according to (2) is overestimated. In formula (2) the correction coefficient is constant $\left(k_{s}=3.55\right)$ independently of the shape and size of the cutout.

Table 4. Comparison of the numerical and semi-analytical values of buckling pressure $p_{c r}$.

\begin{tabular}{|c|c|c|c|}
\hline $\begin{array}{c}\text { Thickness } \\
\boldsymbol{t}[\mathbf{m m}]\end{array}$ & $\begin{array}{c}\text { Equation (1) } \\
\boldsymbol{p}_{c r}[\mathbf{M P a}]\end{array}$ & $\begin{array}{c}\text { Equation (2) } \\
\boldsymbol{p}_{c r}[\mathbf{M P a}]\end{array}$ & $\begin{array}{c}\text { FEM } \\
\boldsymbol{p}_{c r}[\mathbf{M P a}]\end{array}$ \\
\hline 0.5 & 7.784 & 24.495 & 14.218 \\
\hline 1.0 & 31.135 & 97.980 & 56.536 \\
\hline 1.5 & 70.055 & 220.455 & 126.432 \\
\hline
\end{tabular}

\section{I.2 Nonlinear elastic analysis of buckling and post-buckling behavior}

As it is mentioned above, the presented now numerical analysis simulates the real test with the use of a tension machine. It is assumed that the plates are subjected to uniform, uniaxial tensile load, which is controlled by the imposed displacement UX of the right edge (Fig. 2). The final value of the displacement $U X$ is constant and equal to $U X=7 \mathrm{~mm}$. The maximal elongation of the applied material is equal to $\mathrm{A}=3[\%]$. The length of the plate edge is equal to $\mathrm{L}=200 \mathrm{~mm}$, thus it can be assumed that the plate could be stretched maximally of the value $\Delta \mathrm{U}=0.03 \times 200=6 \mathrm{~mm}$. It is worth noting that for the greater values of $\Delta \mathrm{U}$ the investigated plate certainly will be destroyed. Therefore it seems that a proposed final value of displacement UX is reasonable. The applied load is divided into 850 constant steps during the nonlinear analysis. The Newton - Raphson algorithm is applied. Moreover, to trigger the buckling phenomenon, a small geometrical imperfection is introduced. The shape of the imperfection is identical to the first buckling mode, which is presented in Fig. 6 (the load controlled by pressure $p_{c r}$ ). The maximal magnitude of the imperfection (the points marked as $\mathrm{MX}$ in Fig. 6) is relatively small and is equal to $\mathrm{f}=0.005 \mathrm{~mm}$.

\subsubsection{Plate with a circular hole}

The four characteristic relationships for the plate with a circular hole are presented in Fig. 11. As it can be observed (Fig. 11a) the axial tensile force increases linearly with increasing the horizontal displacement UX during the simulations.

(a)

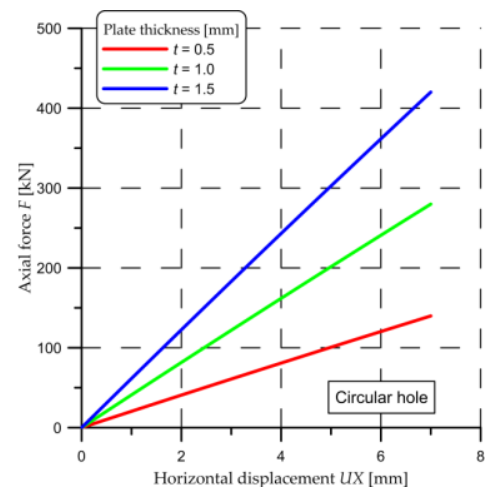

(b)

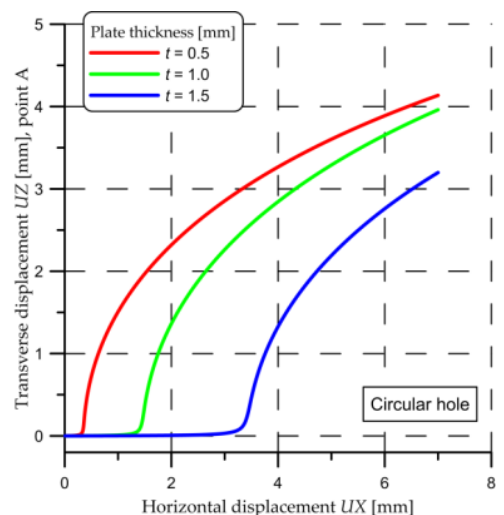

(c)

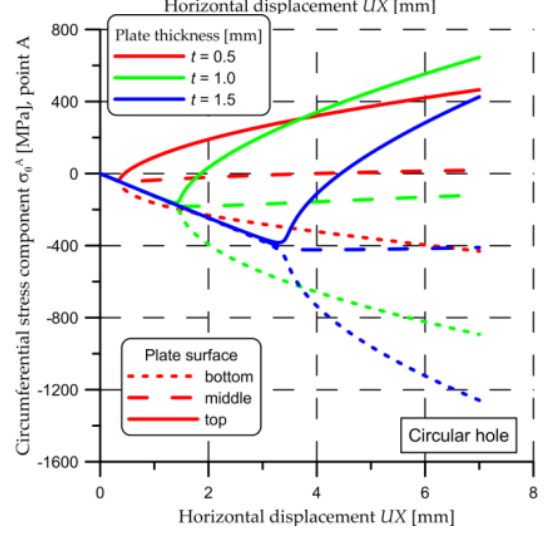


(d)

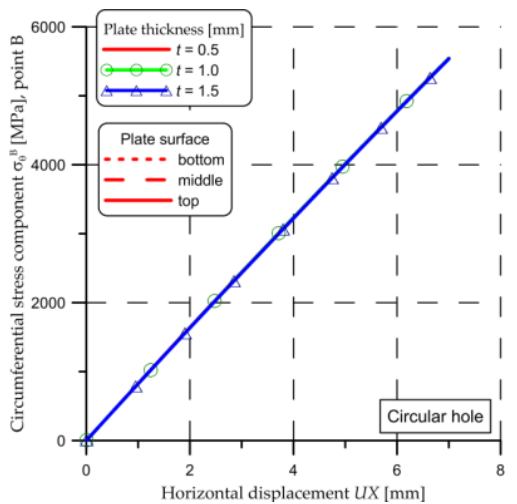

Fig. 11 Relationships between horizontal displacement (load) UX and: (a) axial force F; (b) transverse displacement UZ; (c) circumferential stress component $\sigma \theta^{\mathrm{A}}$ at point $\mathrm{A}$; (d) circumferential stress component $\sigma_{\theta}{ }^{\mathrm{B}}$ at point $\mathrm{B}$. Results for plates with circular holes.

However, the component of displacement UZ at point A (Fig. $11 \mathrm{~b}$ ), which is initially almost equal to zero, suddenly increases. The value of the UX (load), when this process is triggered, depends on the thickness of the plate. For thicker plates, the value of UX is greater. A very characteristic effect can be observed in Fig. 11c, where the stress components $\sigma_{\theta}{ }^{\mathrm{A}}$ measured at the bottom, middle, and top surfaces are presented. Initially, all of these stresses are almost identical. However, when the loss of stability occurs, these quantities start to be significantly different. A similar plot is presented by Kremer and Schürmann [38] in the case of composite plates with cutouts. Generally, the membrane state of stress at point $\mathrm{A}$ is disturbed and the local bending in the vicinity of point $\mathrm{A}$ is present now. The moment, when the loss of stability occurs, can be estimated by finding the minimal value of the stress $\sigma_{\theta}{ }^{\mathrm{A}}$, measured on the top or bottom surface of the plate at point A. The choice of the surface (top or bottom) depends on where the clear minimum can be found. In other words which surface starts to be stretched. The introduction of the described above criterion of stability is very simple and it can be applied in the case when the plasticity effects are taken into account. Finally, the circumferential stress components $\sigma_{\theta}{ }^{\mathrm{B}}$ at point $\mathrm{B}$ also measured on the bottom, middle and top surface as a function of the displacement UX are depicted in Fig.11d. It is visible that the loss of stability has no impact on these parameters. Therefore, taking under consideration the relationships depicted in Fig. 11a and 11d, it can be stressed here that the loss of stability has strictly local character. The obtained critical parameters, namely horizontal displacement UX, axial force $F$, the circumferential stress components $\sigma_{\theta}{ }^{\mathrm{A}}, \sigma_{\theta}{ }^{\mathrm{B}}$ measured at points $\mathrm{A}$ and $\mathrm{B}$, respectively, are collected in Table 5 for the plate with a circular hole. The obtained results are quite similar to those, which are presented in Table 3. As before the magnitude of the registered stresses (Table 5) are very high in comparison with the yield stress of the applied material. Thus, it seems that the effects of plasticity have to be taken into account. The final shape of the buckled plates is depicted in Fig. 12. The normal deflection is not very large in comparison with the final value of the displacement $\mathrm{UX}=7 \mathrm{~mm}$ (load). Depending on the thickness of the plate, the displacement UZ varies from $4.14 \mathrm{~mm}$ to $3.2 \mathrm{~mm}$. Generally, the shapes shown in Fig. 12 are very similar to each other. It is worth stressing that although the shape of the initial geometrical imperfection (Fig. 6) is not symmetric the final shape of deflection is symmetric as those which are depicted in Fig. 9 (load controlled by displacement).

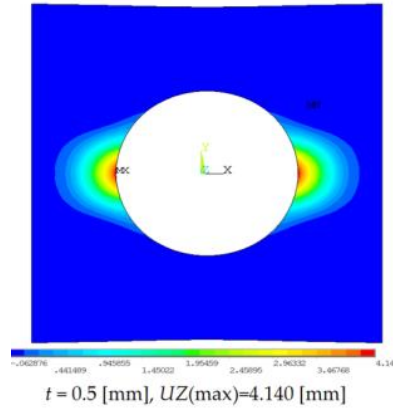

(a)

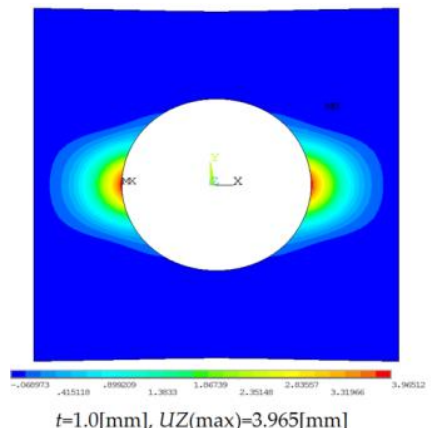

(b)

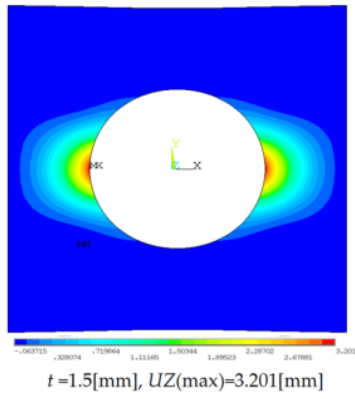

(c)

Fig. 12 Final shape of deflection for plates with circular holes: (a) $t=$ $0.5 \mathrm{~mm}$; (b) $\mathrm{t}=1.0 \mathrm{~mm}$; (c) $\mathrm{t}=1.5 \mathrm{~mm}$.

\subsubsection{Plate with vertically oriented elliptical cutout}

Fig. 13 presents the plots similar to those which are shown in Fig. $11 \mathrm{~b}$ and $11 \mathrm{c}$ for a plate with a circular hole. The relationships between the horizontal displacement UX and axial force or circumferential stress component at point $\mathrm{B}$ are qualitatively identical. Therefore they are not presented here. In the case of vertically oriented elliptic cut-out, the critical values of displacement UX and corresponding values of axial forces are significantly smaller than in the case of a circular hole (Table 5). It is connected with the fact that the radius of curvature at point $\mathrm{A}$ is larger than in the case of a circular hole. The stresses at points A and B are also smaller. For the plate of thickness $\mathrm{t}=0.5 \mathrm{~mm}$ and $\mathrm{t}=1.0 \mathrm{~mm}$ the loss of stability is possible in the elastic range. However, the stresses at point B do not significantly exceed the yield stress of the applied material. Besides, the obtained results are quite comparable with those which are collected in Table 3. It is worth noting here that the final shape of the plate of thickness $t=0.5 \mathrm{~mm}$ is quite different in comparison with the rest of the studied cases (Fig. 14). The left vicinity of the cutout (edge) deforms in the opposite direction than the right edge. It is caused by the fact that in this part of the structure there is no assumed geometrical imperfection. Thus this part of the structure can deform freely. When the loss of stability occurs both directions of deformation are equally probable. The magnitude of transverse deflection is almost two times larger in comparison with the deflection obtained for a circular hole (Fig. 12). 


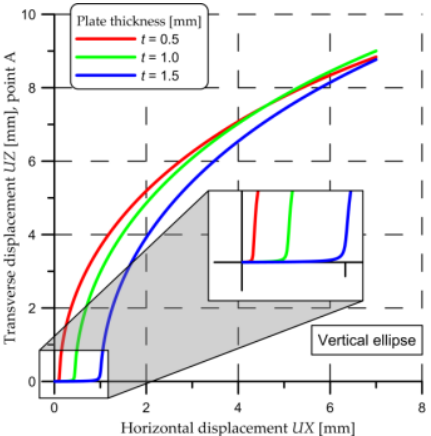

(a)

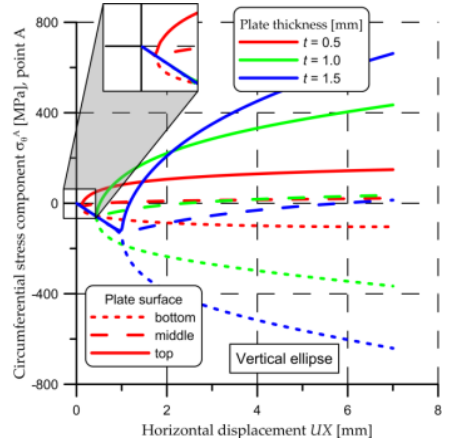

(b)
Fig. 13 Relationships between horizontal displacement UX and: (a) transverse displacement UZ; (b) circumferential stress component $\sigma_{\theta}{ }^{\mathrm{A}}$ at point $\mathrm{A}$ for plates with vertically oriented elliptic cutouts.

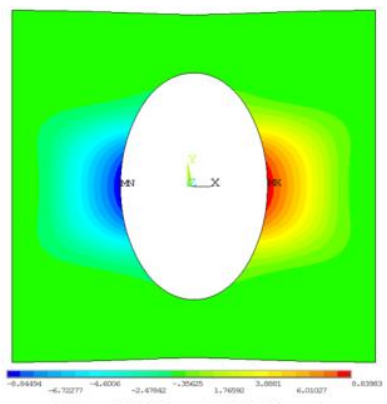

$t=0.5[\mathrm{~mm}], U Z(\max )=8.840[\mathrm{~mm}]$

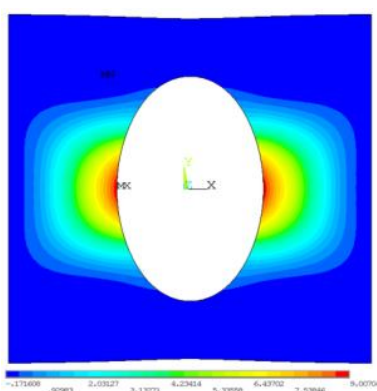

$t=1.0[\mathrm{~mm}], U Z(\max )=9.007[\mathrm{~mm}]$

(a)

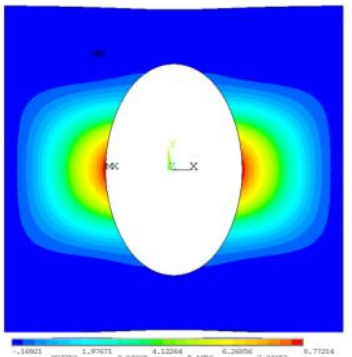

(b)

(c)

Fig. 14 Final shape of deflection for the plate with vertically oriented elliptical cutout: (a) $\mathrm{t}=0.5 \mathrm{~mm}$; (b) $\mathrm{t}=1.0 \mathrm{~mm}$; (c) $\mathrm{t}=1.5 \mathrm{~mm}$.

\subsubsection{Plate with horizontally oriented elliptical cutout}

In the case of the horizontally oriented elliptical cut-out, the loss of stability is not observed for all analyzed cases. The character of the relationships between the horizontal displacement UX and axial force or circumferential stress components at point $\mathrm{B}$ are qualitatively identical as in the case of a circular hole or vertically oriented cutout. The relationship between displacement UX and the transverse displacement UZ, depicted in Fig. 15a is quite different in comparison with the corresponding plots presented above. Although the geometrical imperfection is introduced the direction of deformation is opposite to the imperfection, which is visible in Fig. 15a. In other words, the initial plate becomes more "flat" during the simulation. Additionally, the circumferential stress components $\sigma_{\theta}{ }^{\mathrm{A}}$, shown in Fig. $15 \mathrm{~b}$, do not change their character during the simulations. For all studied cases, the

obtained values of the stresses are almost identical, with no respect to where they are measured (bottom, middle, or top surface).

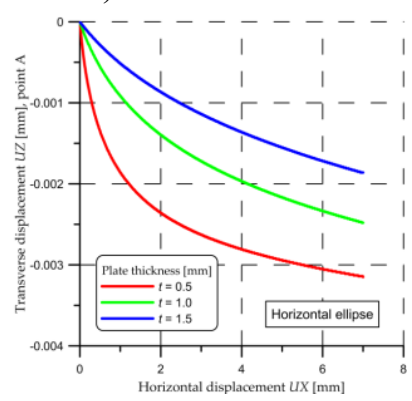

(a)

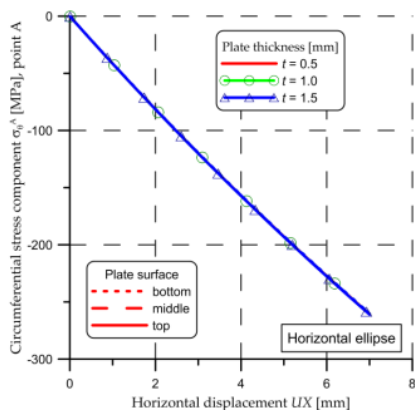

(b)
Fig. 15 Relationships between horizontal displacement (load) UX and: (a) transverse displacement UZ; (b) circumferential stress component $\sigma \theta \mathrm{A}$ at point $\mathrm{A}$ for plates with horizontally oriented elliptic cutouts.

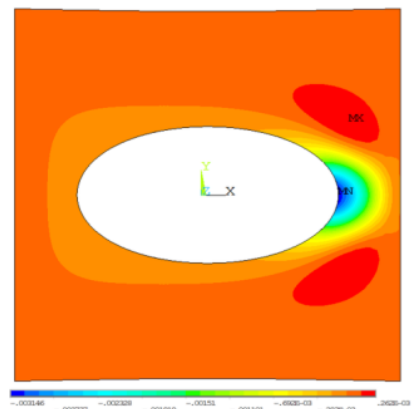

$t=0.5[\mathrm{~mm}], U Z(\min )=-0.003[\mathrm{~mm}]$

(a)

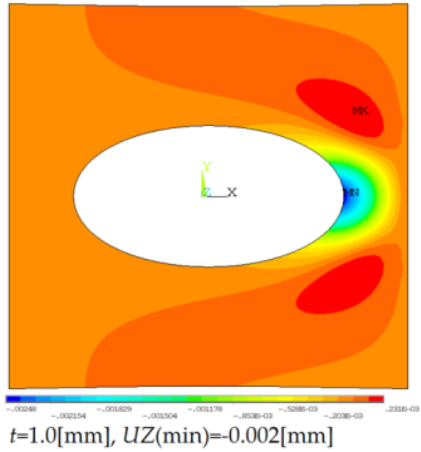

(b)

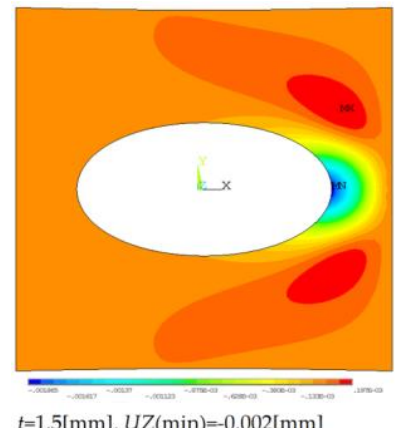

(c)

Fig. 16 Final shape of deflection for the plate with horizontally oriented elliptical cutout: (a) $\mathrm{t}=0.5 \mathrm{~mm}$; (b) $\mathrm{t}=1.0 \mathrm{~mm}$; (c) $\mathrm{t}=$ $1.5 \mathrm{~mm}$.

Table 5. Results of simulations. The plasticity of the material is not taken into account.

\begin{tabular}{|c|c|c|c|c|}
\hline $\begin{array}{c}\text { Thickness } \\
\boldsymbol{t}[\mathbf{m m}]\end{array}$ & $\begin{array}{c}\boldsymbol{U} \boldsymbol{X} \\
{[\mathbf{m m}]^{*}}\end{array}$ & $\begin{array}{c}\text { Axial force } \\
\boldsymbol{F}[\mathbf{k N}]\end{array}$ & $\begin{array}{c}\boldsymbol{\sigma}_{\boldsymbol{\theta}}{ }^{\mathbf{A}} \\
{[\mathbf{M P a}]}\end{array}$ & $\begin{array}{c}\boldsymbol{\sigma}_{\boldsymbol{\theta}}{ }^{\mathbf{B}} \\
{[\mathbf{M P a}]}\end{array}$ \\
\hline \multicolumn{5}{|c|}{ Circular hole } \\
\hline 0.5 & 0.329 & 6.773 & -41.133 & 272.503 \\
\hline 1.0 & 1.392 & 56.996 & -172.643 & 1142.223 \\
\hline 1.5 & 3.294 & 200.847 & -403.457 & 2666.644 \\
\hline \multicolumn{5}{|c|}{ Vertically oriented elliptical cutout } \\
\hline 0.5 & 0.099 & 1.491 & -13.112 & 113.962 \\
\hline
\end{tabular}




\begin{tabular}{|l|c|c|c|c|}
\hline 1.0 & 0.420 & 12.662 & -55.655 & 482.869 \\
\hline 1.5 & 0.963 & 43.522 & -127.376 & 1102.199 \\
\hline \multicolumn{5}{|c|}{ Horizontally oriented elliptical cutout } \\
\hline 0.5 & \multicolumn{3}{|c|}{ The loss of stability is not observed } \\
\cline { 1 - 1 } 1.0 & \\
\cline { 1 - 1 } 1.5 &
\end{tabular}

*UX - the critical value of horizontal displacement for which the loss of stability occurs.

The main reason, why in this case the loss of stability is not present, is that the tensile stresses $\sigma_{\theta}{ }^{\mathrm{B}}$ at point $\mathrm{B}$ are dramatically larger than the compressive stresses $\sigma_{\theta}{ }^{\mathrm{A}}$ at point A. The large tension causes that the stiffness of the structure increases during the simulation and the loss of stability is not possible. It should be stressed here that the magnitude of the transverse displacement UZ decreases with increasing the thickness of the structure. This effect can be observed in Figure 15a and Figure 16.

\subsection{Nonlinear analysis with plasticity taken into account}

As it is shown in the all tables presented in the previous subsections, the magnitude of stresses, especially the tensile stresses at point $\mathrm{B}$, is much greater in comparison with the yield stress of the material of the plate. One can be said, that the loss of stability always occurs together with plasticity effects. In the case of thin plates $(\mathrm{t}=0.5 \mathrm{~mm})$ the estimated stresses have the magnitude of the yield stress of the material. However, for the thicker structures, these stresses are significantly higher in comparison with the yield stress. Thus, it can be assumed that the plasticity effects significantly affect the buckling and post-buckling behavior of the investigated structure. In order to verify this influence, the simple model of plasticity is introduced, namely bilinear isotropic hardening with a relatively small value of tangent modulus $\mathrm{E}_{\mathrm{T}}=1390 \mathrm{MPa}$. This value can be estimated under the assumption, that the maximal elongation of the material $\mathrm{A}=3[\%]$ is obtained with the stress of magnitude $\mathrm{R}_{\mathrm{m}}=125 \mathrm{MPa}$. The last quantity is the average value of the $R_{m}$ calculated for the values mentioned in the section. The shape of the applied geometrical imperfection is identical as described in section 3.2 of this work.

\subsubsection{Plate with a circular hole}

The effect of plasticity is visible in Fig. 17a, where the relationship between the horizontal displacement UX (load) and axial force $F$ is not linear anymore. It should be stressed that this effect is not caused by the loss of stability but caused by the plasticity of the material. As it is shown in Fig. 17d, the circumferential components of stress $\sigma_{\theta}{ }^{\mathrm{B}}$, measured at the bottom, middle and top surface are almost identical. Moreover, these stresses are also identical for all studied thicknesses of the plate. It should be noted the yield stress of the plate material is initially exceeded at point B. The local loss of stability is observed in the case of plates of thicknesses $t=0.5$ $\mathrm{mm}$ and $\mathrm{t}=1.0 \mathrm{~mm}$ (Fig. 17b). The value of the critical load UX for the plate of thickness $\mathrm{t}=0.5 \mathrm{~mm}$, Table 6 , is slightly smaller in comparison with the corresponding value obtained for the elastic plate (Table 5). However, in the case of the plate of thickness $\mathrm{t}=1.0 \mathrm{~mm}$ the critical value of the load is significantly greater. The relationships between the horizontal displacement $U X$ and the stress component at point $\mathrm{A} \sigma_{\theta}{ }^{\mathrm{A}}$, depicted in Fig. 17c are quite different than in the case of elastic analysis. The moment, when the plasticity effects start to be active is visible in Fig. 17c. Moreover, when the loss of stability occurs, the shape of the curves, which describe the stresses measured at the bottom, middle, and top surface of the plate, are also quite different. Above, the curves, which describe the stresses measured at the bottom and top surface of the plate, are almost symmetrical with respect to the curve, which represents the stresses at the middle surface. Now, when the loss of stability occurs, all stresses increase. It is worth noting that the plasticity is also active in this case for the plate of thickness $\mathrm{t}=1.0 \mathrm{~mm}$ and $\mathrm{t}=1.5 \mathrm{~mm}$. Additionally, the distribution of the plastic strain equivalent at the moment, when the loss of stability occurs is shown in Fig. 18. In the case of the plate with thickness $\mathrm{t}=0.5 \mathrm{~mm}$ the plastic strains do not occur throughout the whole plate. They are localized in the vicinity of point $B$. However, in the case of the plate of thickness $\mathrm{t}=1.0 \mathrm{~mm}$, the plastic strains include the whole width of the investigated structure. It should be explained, why for the plate of thickness $\mathrm{t}=1.5 \mathrm{~mm}$ the loss of stability does not occur. The stress magnitude at point $\mathrm{A}$ is reduced by the plasticity effects below the level, where the loss of stability is possible. The magnitude of stresses, which are presented in Table 5 for the plate of thickness $\mathrm{t}=1.5 \mathrm{~mm}$ is very high. It is not possible to obtain this level of stress when the plasticity of the material is taken into account. The transverse displacements UZ obtained for the final value of the load UX are presented in Fig. 19. For the plates, where the loss of stability occurs, the magnitude of transverse displacement UZ is similar as in the case of elastic analysis.

(a)
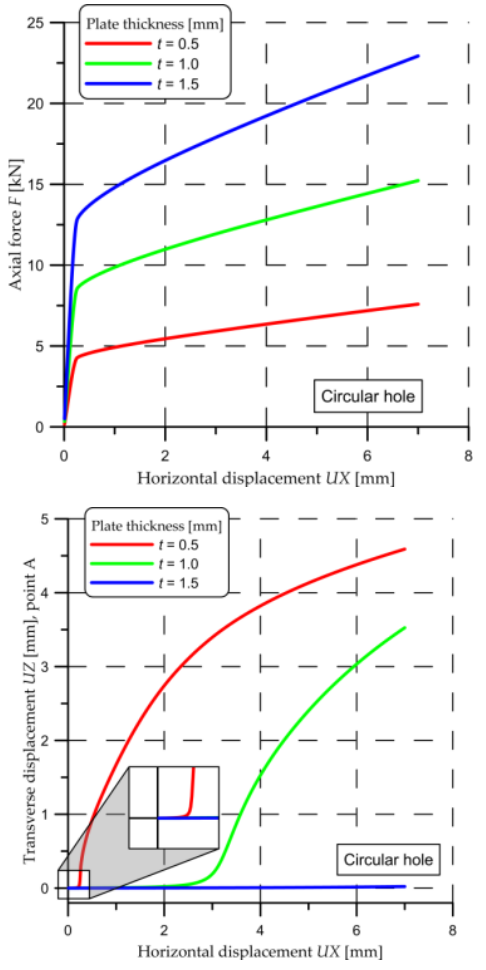
(c)

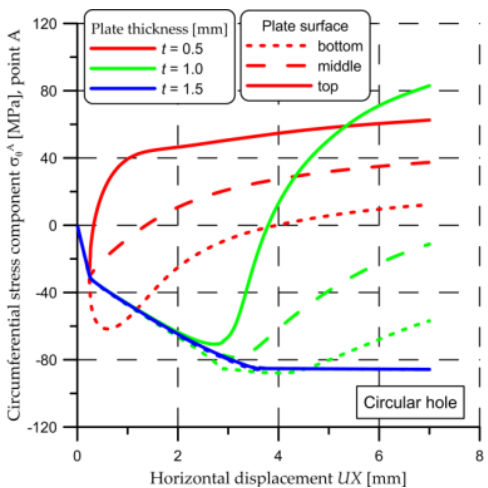

(d)

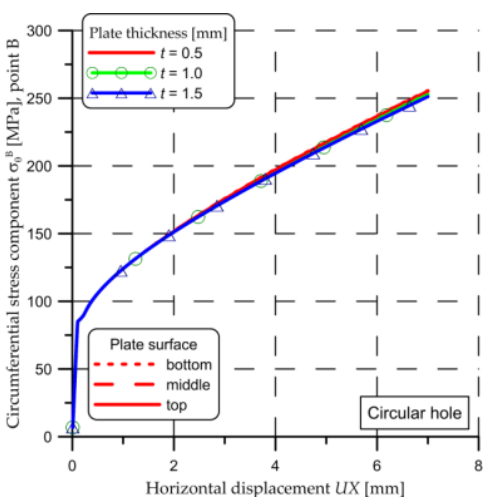

Fig. 17 Relationships between horizontal displacement (load) UX and: (a) axial force F; (b) transverse displacement UZ; (c) circumferential stress component $\sigma_{\theta}{ }^{\mathrm{A}}$ at point $\mathrm{A}$; (d) circumferential stress component $\sigma_{\theta}{ }^{\mathrm{B}}$ at point $\mathrm{B}$. Results for plates with circular holes.

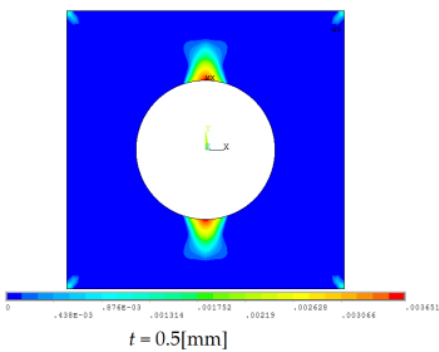

(a)

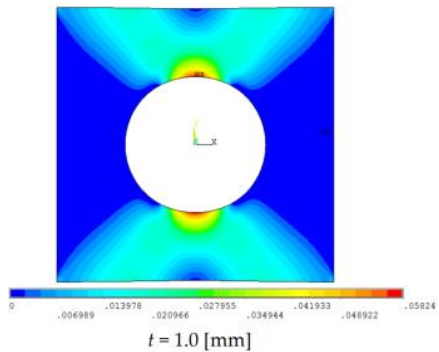

(b)
Fig. 18 The distribution of equivalent of plastic strains for plate with circular hole with thickness: (a) $\mathrm{t}=0.5 \mathrm{~mm}$; (b) $\mathrm{t}=1.0 \mathrm{~mm}$.

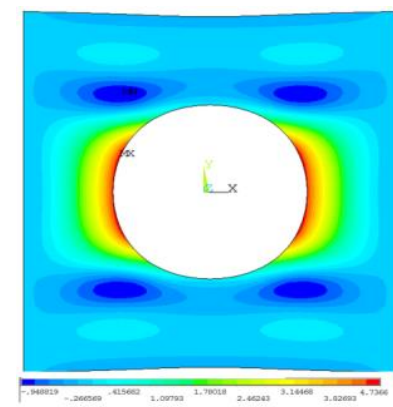

$t=0.5[\mathrm{~mm}], \quad U Z(\max )=4.737[\mathrm{~mm}]$

(a)

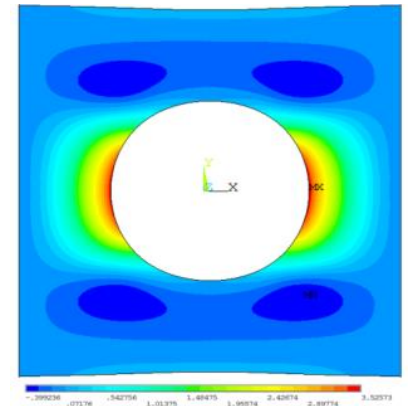

$t=1.0[\mathrm{~mm}], \quad U Z(\max )=3.526[\mathrm{~mm}]$

(b)

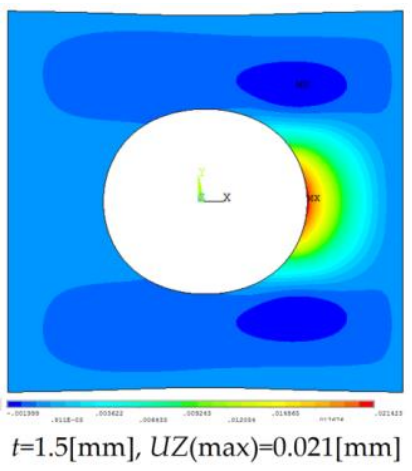

(c)

Fig. 19 The final shape of plate with circular hole with thickness: (a) $\mathrm{t}=0.5 \mathrm{~mm}$; (b) $\mathrm{t}=0.5 \mathrm{~mm}$; (c) $\mathrm{t}=1.5 \mathrm{~mm}$

\subsubsection{Plate with vertically oriented elliptical cutout}

In the case of the plates with vertically oriented elliptic cutouts, the relationships between the horizontal displacement $\mathrm{UX}$ and axial force $\mathrm{F}$ as well as the horizontal dis-placement $\mathrm{UX}$ and the circumferential stress component $\sigma_{\theta}{ }^{\mathrm{B}}$ at point $\mathrm{B}$ are qualitatively identical as presented above. Thus they are not shown and discussed here. As it is depicted in Fig. 20a, for all studied structures the loss of stability is present. In the case of the plate of thickness $\mathrm{t}=0.5 \mathrm{~mm}$ the obtained critical parameters, collected in Table 6 are very similar to those, which are in the corresponding Table 5. For this case, when the loss of stability occurs, the plastic strains are almost absent. The plastic strains are observed in the close vicinity of point B as is shown in Fig. 21. However, for the rest of the investigated structures, the loss of stability is observed for the significantly greater value of the load (horizontal displacement UX). Moreover, for the rest structures, when the loss of stability occurs, the size of the plastic zones increases and includes the whole width of the plate. The plasticity effects decrease the absolute value of the critical stresses $\sigma_{\theta}{ }^{\mathrm{A}}$ at point A. The greatest reduction is observed for the plate of thickness $\mathrm{t}=1.5 \mathrm{~mm}$. The stresses $\sigma_{\theta}{ }^{\mathrm{B}}$ at point $\mathrm{B}$ are dramatically lower because of the plastic hardening. The shape of the curves describing the circumferential stress components $\sigma_{\theta}{ }^{\mathrm{A}}$ at the bottom, middle, and top surfaces, Fig. 20b, have a similar character as in the case of the plates with a circular hole. In all cases the curves after the loss of stability increase. The magnitude of the final transverse displacement UZ, presented in Fig. 22, is similar to those, which are presented in Fig. 14 except the plate of thickness $t=1.5 \mathrm{~mm}$.

(a)

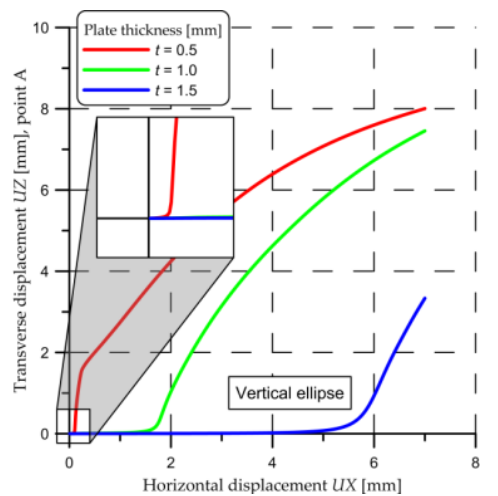


(b)

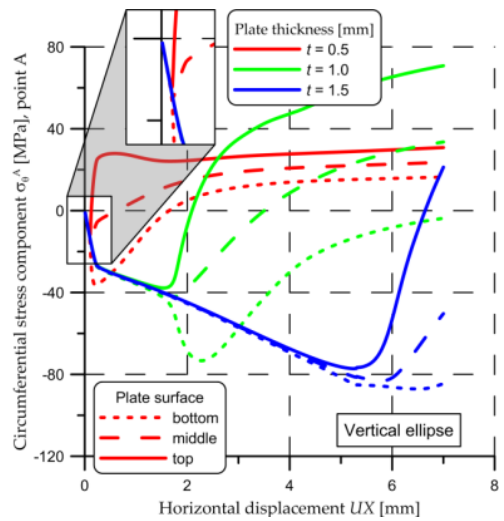

Fig. 20 Relationships between horizontal displacement UX and: (a) transverse displacement UZ; (b) circumferential stress component $\sigma_{\theta}{ }^{\mathrm{A}}$ at point $\mathrm{A}$ for plates with vertically oriented elliptic cutouts.

In this case, the value of the maximal transverse displacement $\mathrm{UZ}$ is about two times smaller. Additionally, in the case of the plate of thickness $\mathrm{t}=0.5 \mathrm{~mm}$ the shape of deflection is asymmetric, namely the left edge of the cutout displaces in the opposite direction in comparison with the right edge.

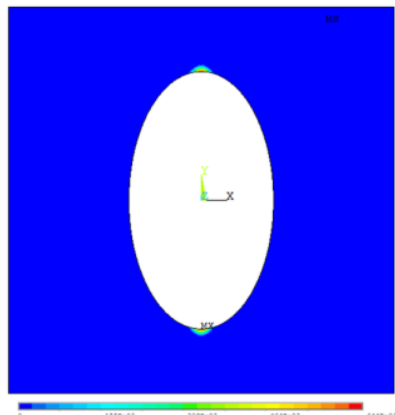

$t=0.5[\mathrm{~mm}]$

(a)

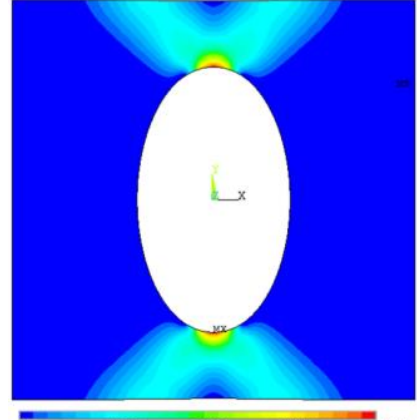

$t=1.0[\mathrm{~mm}]$

(b)

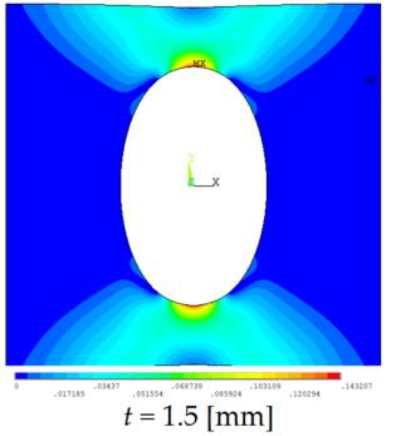

(c)
Fig. 21 The distribution of equivalent of plastic strains for plate with vertically oriented elliptic cutout: (a) $\mathrm{t}=0.5[\mathrm{~mm}]$; (b) $\mathrm{t}=1.0[\mathrm{~mm}]$; (c) $\mathrm{t}=1.5[\mathrm{~mm}]$.

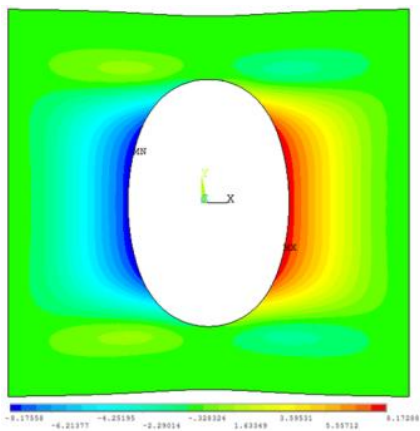

$t=0.5[\mathrm{~mm}], U Z(\max )=8.17[\mathrm{~mm}]$

(a)

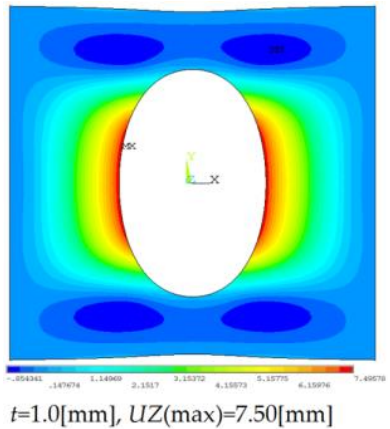

(b)

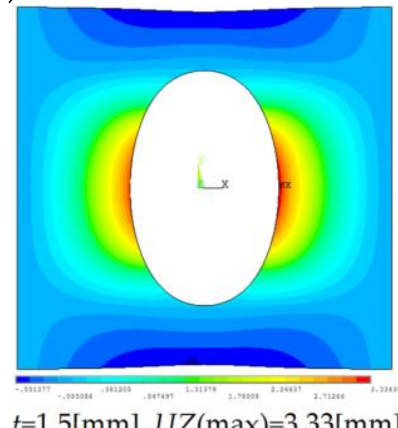

$t=1.5[\mathrm{~mm}], U Z(\max )=3.33[\mathrm{~mm}]$

(c)

Fig. 22 The final shape of plate with vertically oriented elliptic cutout: (a) $\mathrm{t}=0.5[\mathrm{~mm}]$; (b) $\mathrm{t}=1.0[\mathrm{~mm}]$; (c) $\mathrm{t}=1.5[\mathrm{~mm}]$.

\subsubsection{Plate with horizontally oriented elliptical cutout}

Taking under consideration the same reasons as in the case of the plates with vertically oriented elliptic cutouts, the plots representing the relationships between the horizontal displacement UX and the axial force $\mathrm{F}$ and the horizontal displacement UX and the circumferential stress components $\sigma_{\theta}{ }^{\mathrm{B}}$ are not presented here. As is presented earlier the loss of stability is not observed in any case of the plates with horizontally oriented cutouts when the plasticity effects are excluded. However, now the loss of stability occurs only for the plate of thickness $\mathrm{t}=0.5 \mathrm{~mm}$, which is depicted in Fig. $23 \mathrm{a}$. In this case, the circumferential stress components $\sigma_{\theta}{ }^{A}$, measured at the bottom, middle, and top surface of the plate split into three curves, Fig. 23b. The character of these curves is similar to those, which are presented in previous subsections. However now, the stress component $\sigma_{\theta}{ }^{\mathrm{A}}$ at the bottom surface is significantly limited by the plasticity effect. The plasticity zones, presented in Fig. 24, are very large and include the whole width of the plate. The loss of stability occurs with a relatively small value of the critical circumferential stress components $\sigma_{\theta}{ }^{\mathrm{A}, \mathrm{B}}$ at points $\mathrm{A}$ and $\mathrm{B}$, Table 6. It is worth stressing here that the maximal value of the transverse displacement UZ, shown in Fig. 25, is relatively small in comparison with those, which are presented above. This effect can be caused by the fact that the left and the right edges are located very close to the grips of the tension machine. The stiffness of the plate in these zones is significantly higher in comparison with the rest of the plate. It hinders the transverse deflection of the edge of the cut-out. Thus it can be assumed that if the investigated plate was longer 
in the horizontal direction, the loss of stability would occur in any case of thickness.

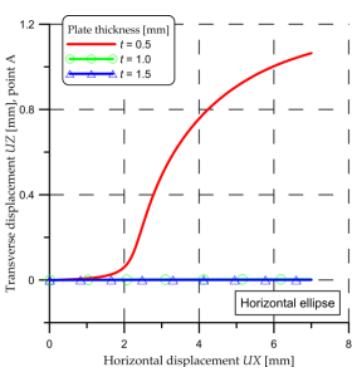

(a)

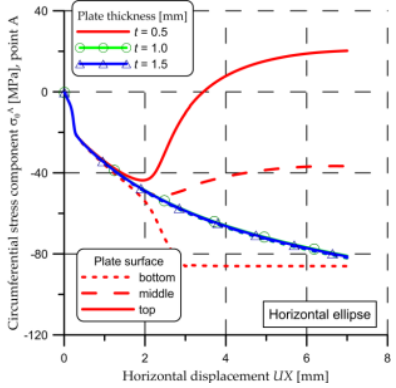

(b)
Fig. 23 Relationships between horizontal displacement UX and: (a) transverse displacement UZ; (b) circumferential stress component $\sigma_{\theta}{ }^{\mathrm{A}}$ at point A for plates with horizontally oriented elliptic cutouts.

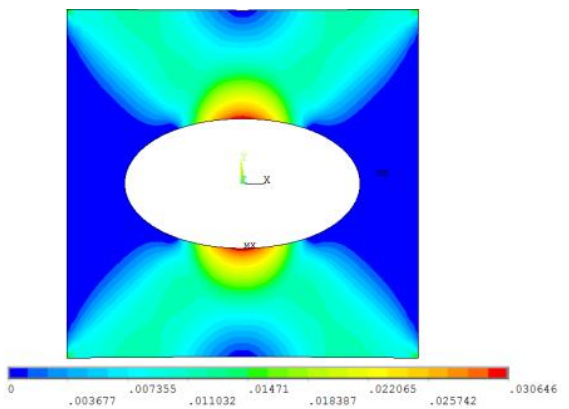

Fig. 24 The distribution of equivalent plastic strains for the plate with horizontally oriented elliptic cutout with thickness $t=0.5[\mathrm{~mm}]$.

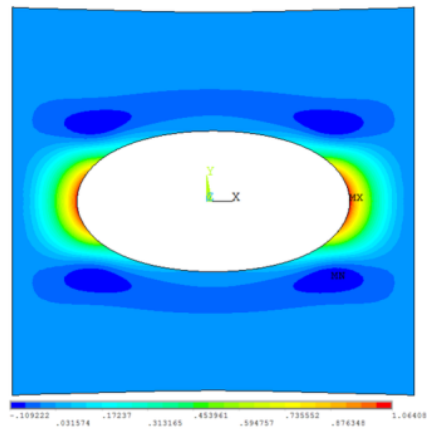

$t=0.5[\mathrm{~mm}], U Z(\max )=1.064[\mathrm{~mm}]$

(a)

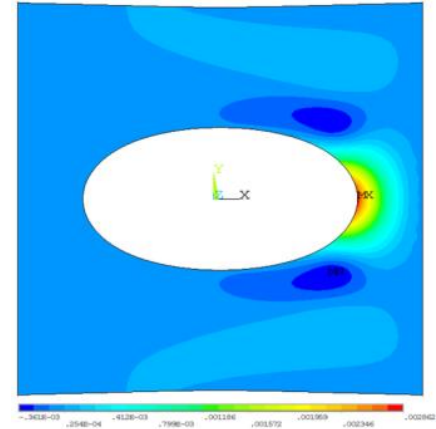

$t=1.0[\mathrm{~mm}], U Z(\max )=0.003[\mathrm{~mm}]$

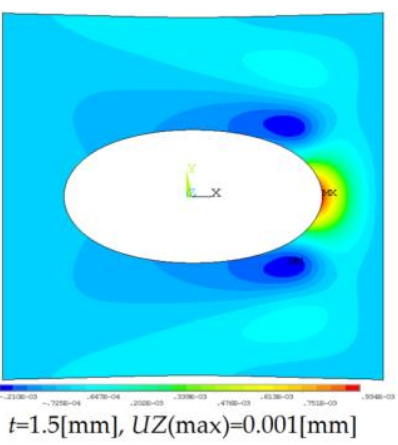

(b)

(c)

Fig. 25 The final shape of plate with horizontally oriented elliptic cutout: (a) $\mathrm{t}=0.5 \mathrm{~mm}$; (b) $\mathrm{t}=1.0 \mathrm{~mm}$; (c) $\mathrm{t}=1.5 \mathrm{~mm}$.

Table 6. Results of simulations. The plasticity of the material is taken into account.

\begin{tabular}{|c|c|c|c|c|}
\hline $\begin{array}{c}\text { Thickness } \\
\boldsymbol{t}[\mathrm{mm}]\end{array}$ & $\begin{array}{c}\boldsymbol{U} \boldsymbol{X} \\
{[\mathbf{m m}]^{*}}\end{array}$ & $\begin{array}{c}\text { Axial force } \\
\boldsymbol{F}[\mathbf{k N}]\end{array}$ & $\begin{array}{c}\boldsymbol{\sigma}_{\boldsymbol{\theta}}{ }^{\mathbf{A}} \\
{[\mathbf{M P a}]}\end{array}$ & $\begin{array}{c}\boldsymbol{\sigma}_{\boldsymbol{\theta}}^{\mathbf{B}} \\
{[\mathbf{M P a}]}\end{array}$ \\
\hline \multicolumn{5}{|c|}{ Circular hole } \\
\hline 0.5 & 0.231 & 4.132 & -28.745 & 90.347 \\
\hline 1.0 & 2.726 & 11.680 & -75.976 & 167.880 \\
\hline 1.5 & \multicolumn{5}{|c|}{ The loss of stability is not observed } \\
\hline \multicolumn{5}{|c|}{ Vertically oriented elliptical cutout } \\
\hline 0.5 & 0.099 & 1.484 & -13.077 & 89.290 \\
\hline 1.0 & 1.540 & 7.582 & -40.209 & 172.195 \\
\hline 1.5 & 5.271 & 15.709 & -81.276 & 288.961 \\
\hline \multicolumn{5}{|c|}{ Horizontally oriented elliptical cutout } \\
\hline 0.5 & 1.935 & 6.503 & -48.127 & 128.555 \\
\hline 1.0 & \multicolumn{5}{|c|}{ The loss of stability is not observed } \\
\hline 1.5 & \multicolumn{5}{|c|}{} \\
\hline
\end{tabular}

*UX - critical value of horizontal displacement for which the loss of stability occurs.

\subsection{Imperfection}

As it is mentioned above the shape of the geometrical imperfection is identical to the shape of the first mode obtained from buckling analysis. It is well known that this shape of the imperfection the most significantly reduces the resistance on the loss of stability of a thin-walled structure. Moreover, in the reality, the shape of the geometrical imperfections may be unrestricted. Thus, it is assumed now that the analysis of the impact of the imperfections on the critical parameters is limited only to the mentioned above shape. The numerical simulations are performed for the several values of maximal magnitude $f$ of geometrical imperfections. The maximum of this value is localized at point A, see Figures 3 and 6. All computations are carried out for the plate with a circular hole with diameter $\mathrm{d}=100 \mathrm{~mm}$ and thickness $\mathrm{t}=1.0$ $\mathrm{mm}$. The plasticity effects are taken into account. The rest of the simulation parameters are the same as those used before. The obtained results are depicted in Figure 26 and the estimated critical parameters are collected presented in Table 7. As before, the relationship between the horizontal displacement UX and the axial force $F$ is shown in Fig. 26a. It is worth noting that the applied shape of geometrical imperfection has no impact on this dependency. Independently on the magnitude of the imperfection amplitude $f$ the all obtained curves overlap. 
(a)

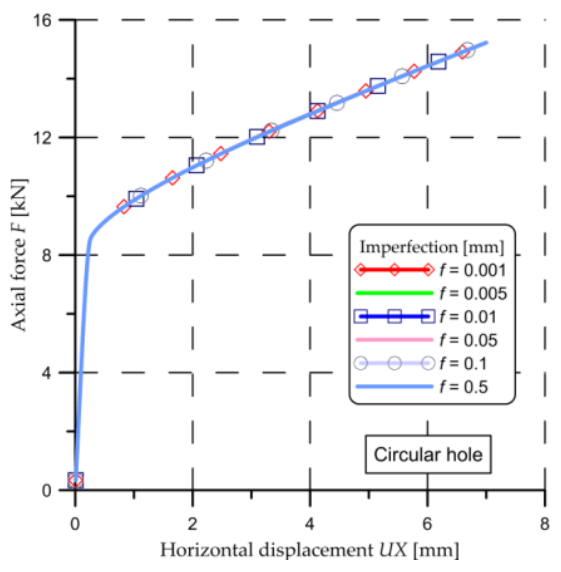

(b)

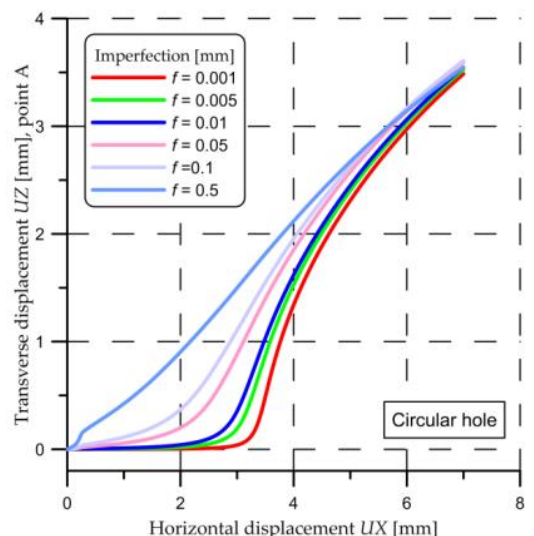

(c)

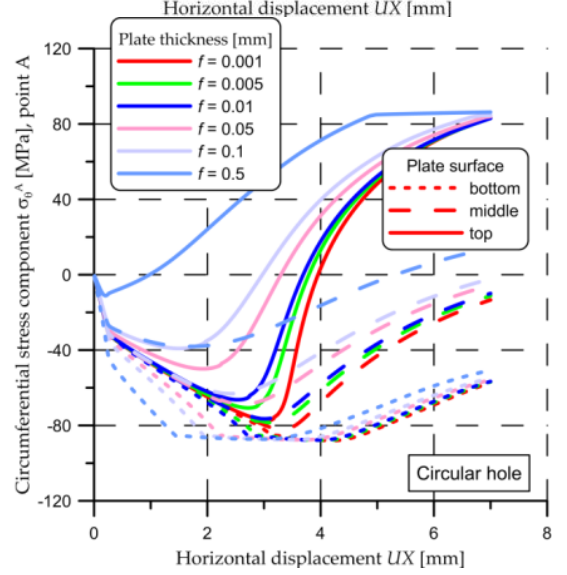

(d)

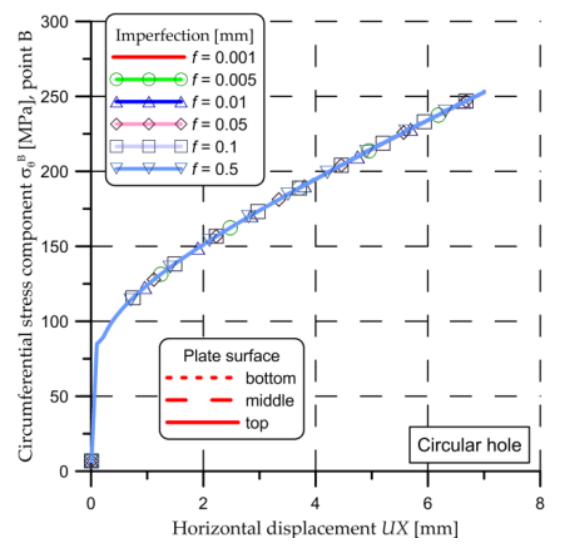

Fig. 26 Relationships between horizontal displacement (load) UX and: (a) axial force $F$; (b) transverse displacement UZ; (c) circumferential stress component $\sigma_{\theta}{ }^{\mathrm{A}}$ at point $\mathrm{A}$; (d) circumferential stress component $\sigma_{\theta}{ }^{\mathrm{B}}$ at point $\mathrm{B}$. Results for plates with circular holes.
The same behavior can be observed in the case of the circumferential stress component $\sigma_{\theta}^{\mathrm{B}}$ at point B, Figure $26 \mathrm{~d}$. As before, all curves overlap each other. However, the significant influence of the magnitude of geometrical imperfection $\mathrm{f}$ is observed in the case of the relationship between the transverse displacement UZ (controlled at point A) and the horizontal displacement UX. As it can be observed in Figure 26b, together with increasing the magnitude of imperfection $\mathrm{f}$, the obtained curves become more smooth. For the magnitude of the imperfection $f$ greater than $\mathrm{f}>0.5[\mathrm{~mm}]$ the classical loss of stability could not be observed. The value of critical horizontal displacement UX, as well as, the absolute value of circumferential stress components $\sigma_{\theta}{ }^{\mathrm{A}}$ and the corresponding value of $\sigma_{\theta}{ }^{\mathrm{B}}$ also decreases (Table 7). Initially, for the relatively small values of the imperfection $f$, the reduction of the values of critical parameters is not very significant. However, together with increasing of the imperfection $f$ this impact is more severe. This effect is also clearly visible in Figure 26c, especially for the stress component $\sigma_{\theta}{ }^{\mathrm{A}}$, controlled at the top surface of the investigated plate.

Table 7. Critical parameters as a function of magnitude of geometrical imperfection. Results for plate with circular hole.

\begin{tabular}{|c|c|c|c|c|}
\hline $\begin{array}{c}\text { Imperfection } \\
\boldsymbol{f}[\mathbf{m m}]\end{array}$ & $\begin{array}{c}\boldsymbol{U} \boldsymbol{X} \\
{[\mathbf{m m}]^{*}}\end{array}$ & $\begin{array}{c}\text { Axial force } \\
\boldsymbol{F}[\mathbf{k N}]\end{array}$ & $\begin{array}{c}\boldsymbol{\sigma}_{\boldsymbol{\theta}^{\mathbf{A}}} \\
{[\mathbf{M P a}]}\end{array}$ & $\begin{array}{c}\boldsymbol{\sigma}_{\boldsymbol{\theta}}{ }^{\mathbf{B}} \\
{[\mathbf{M P a}]}\end{array}$ \\
\hline 0.001 & 3.055 & 11.982 & -80.338 & 175.027 \\
\hline 0.005 & 2.726 & 11.680 & -75.976 & 167.880 \\
\hline 0.010 & 2.536 & 11.502 & -73.240 & 163.665 \\
\hline 0.050 & 1.927 & 10.907 & -62.983 & 149.421 \\
\hline 0.100 & 1.507 & 10.463 & -55.000 & 138.705 \\
\hline 0.500 & 0.206 & 7.756 & -22.827 & 88.929 \\
\hline
\end{tabular}

*UX - critical value of horizontal displacement for which the loss of stability occurs.

\section{CONCLUSIONS}

At the very beginning of the work, the linear buckling analysis is performed in order to estimate the appropriate size of the cutouts for further nonlinear analysis. It is assumed that for this size of the hole the circumferential stress components $\sigma_{\theta}{ }^{\mathrm{A}, \mathrm{B}}$ are comparable with the magnitude of the yield stress of the material of the plate. It occurs that this assumption satisfies the circular hole of diameter $\mathrm{d}=100 \mathrm{~mm}$ and corresponding vertically and horizontally oriented ellipses of the semi-axis length $\mathrm{a}=75 \mathrm{~mm}$ and $\mathrm{b}=133.333 \mathrm{~mm}$. If the load is applied by the uniform axial displacement applied on every point, which is located on the vertical edge of the plate (Fig. 4) thus the deformation pattern is quite different in comparison with the situation when the load is controlled by the axial pressure on the same edge. In the first case, the global stiffness of the structure is greater in comparison with the second case. Therefore the significant increase in the value of the axial reaction in the case of load controlled by displacement (Table 2,3 and 5,6) is observed. The lowest critical value of the load is obtained in the case of the vertically oriented elliptic 
cutouts. In the case of the geometrically nonlinear analysis, the loss of stability is observed for all plates with circular and vertically oriented elliptic cutouts. Moreover, the new criterion of the loss of stability is introduced. This criterion is based on the minimum of the circumferential stress component, which is measured on the bottom or the top of the plate surface.

The critical parameters, which are identified with the use of the mentioned criterion, Table 5, are comparable with those, which are obtained from linear buckling analysis, Table 3 . The observed discrepancies may be caused by the fact, that in the case of linear analysis the geometrical nonlinearities are not included.

The local character of the observed loss of stability is confirmed by relationships between the horizontal displacement UX and the axial force F or the horizontal displacement UX and the circumferential component of stress $\sigma_{\theta}{ }^{B}$, measured at point $B$, regardless of whether the plasticity effects are taken into account or not. Generally, the registered stress values significantly exceed the yield stress of the material of the plates. Thus the plasticity effects have to be taken into account. If the plasticity effects are not significant, the obtained values are comparable with those which are provided by an analysis conducted in the elastic range only. It is observed for plates of thickness $\mathrm{t}=0.5 \mathrm{~mm}$ with circular and vertically oriented cutouts. However, for the other studied structures, the plasticity effects dominate. It causes that the critical value of the horizontal displacement UX is greater in comparison with the values obtained from the nonlinear elastic analysis. Because of that, the loss of stability is not observed for the thickest plate with the circular hole. However, the introduction of the plasticity effects may also cause an opposite result. As an example, here can be quoted the case of the thinnest plate with horizontally oriented elliptic cutout, where the loss of stability occurs when the plasticity is taken into account. Besides, the presence of the plasticity effects radically decreases the critical axial force. However, this effect is not directly connected with the loss of stability.

It is worth noting that the character of the curves, which represent the relationships between the horizontal displacement UX and the circumferential stress components $\sigma_{\theta}{ }^{\mathrm{A}}$ are quite different in comparison with those which are obtained when the plasticity effects are not taken into account. Finally, the geometrical imperfections have no impact on the global stability of the investigated structure. They significantly affect the value of the critical horizontal dis-placement UX. If the magnitude of imperfection increases, the critical value of the dis-placement UX will decrease.

It is worth stressing here that the local loss of stability is the most probable in reality (where the plasticity effects are naturally present) for the thinnest plate with the vertically oriented elliptical hole. On the contrary to this case, the most persistent against local buckling is the thicker plate with the horizontally oriented elliptical cut-out. The decisive impact on the appearing local loss of stability possesses the radius of the curvature of the hole. For the increasing radius of curvature, the probability of the loss of stability also increases. Finally, the recommendation for experimental studies is as follows: the ratio between the longer axis length of the ellipse to the edge length of the plate about 0.67 , the ratio of the axes of the ellipse about 0.56 , and the ratio of the plate thickness to its length 0.0025 .

The local loss of stability of the uniformly stretched plates with cutouts is investigated in the paper. The numerical analyses were performed for several cases such as:

1. linear buckling with loading controlled by tension stresses,

2. Linear buckling with loading controlled by displacements,

3. Non-linear buckling and post-buckling analysis,

4. Non-linear analysis with plasticity,

5. Non-linear analysis with plasticity and imperfection.

Summarizing, the obtained results of the above-mentioned studies justify the following conclusions:

1. The tension buckling may occur in metallic thin plates with cut-outs subjected only to tensile loads.

2. The method how the tension load is applied to the plate (controlled by pressure or displacement) has a significant influence on tension buckling behavior.

3. In the case of the linear buckling, the higher critical axial forces were achieved for displacement controlled load.

4. The loss of stability is more probable for plates with a higher ratio of hole diameter to the width of the plate.

5. The applied two different theoretical solutions significantly differ from each other and FEM results.

6. The numerical analyses of tension buckling require the application of the elastic-plastic material behavior.

7. The new criterion of the loss of stability is introduced for the plate with cut-outs. This criterion is based on the minimum of the circumferential stress component, which is measured on the bottom or the top of the plate surface.

8. The largest risk of tension buckling was observed for vertically oriented elliptic cut-out, which agrees with experimental observations for tensile tests of steel plates (such effect was more visible in the plate with a rectangular hole than circular one),

9. The dimensions of the cut-outs for the further experimental study were determined.

Finally, it should be stressed here that our study is limited to the isotropic materials, for which the available different models of the material behavior after exceeding the yield point. This is rather very difficult in the case of composite materials, where the progressive failure needs to be modeled. Moreover, this kind of analysis can be also performed for the other shapes of the cut-outs. As is mentioned in the introduction, in the next future we are going to perform experimental tests with the use of the DIC in order to confirm the obtained numerical results.

\section{REFERENCES}

[1] D. Bushnell, "Computerized buckling analysis of shells, Mechanics of elastic stability," 9, Martinus Nijhoff Publishers, Dordrecht, 1985.

[2] A. Muc, M. Chwał, M. Barski, "Remarks on experimental and theoretical investigations of buckling loads for laminated plates and shell structures, " Compos. Struct. vol. 230, pp. 861-874, 2018. 
[3] M. Shahmardani, P. Ståhle, M.S. Islam, S. Kao-Walter, "Numerical Simulation of Buckling and Post-Buckling Behavior of a Central Notched Thin Aluminum Foil with Nonlinearity in Consideration," Metals vol.10, 582. doi:10.3390/met10050582, 2020

[4] A. Takano, R. Mizukami, R. Kitamura, "Buckling of Rectangular Composite Pipes under Torsion", Appl. Sci. 11, 1342. https://doi.org/10.3390/app11031342, 2021.

[5] J. Krużelecki, A. Stawiarski, "Optimal design of thinwalled columns for buckling under loadings controlled by displacements," Structural and Multidisciplinary Optimization vol. 42, pp. 305-314, 2010

[6] P. Romanowicz, "Experimental and numerical estimation of the damage level in multilayered composite plates," Mater. Werkst. vol.49, pp. 591-605, 2018.

[7] P.J. Romanowicz, B. Szybiński, M. Wygoda, "Application of DIC Method in the Analysis of Stress Concentration and Plastic Zone Development Problems," Materials 13, 3460. doi:10.3390/ma13163460, 2020.

[8] J.C. Yao, "Buckling of truncated hemisphere under axial tension," AIAA Journal vol. 1, pp. 2316-2319, 1963.

[9] K. Magnucki, P. Jasion, M. Rodak, "Strength and buckling of an untypical dished head of a cylindrical pressure vessel," Int. J. Pres. Ves. Pip. vol. 161, pp. 1721, 2018.

[10] N. Friedl, F.G. Rammerstorfer, F.D. Fisher, "Buckling of stretched strips.”, Comput. \& Struct. vol. 78, pp. 185190, 2000.

[11] Y.T. Zhang, Y.B. Fu, "A micromechanical model of woven fabric and its application to the analysis of buckling under uniaxial tension Part 1: The micromechanical model." Int. J. Eng. Sci. vol. 38, pp. 1895-1906, 2000.

[12] Y.T. Zhang, Y.B. Fu, "A micro-mechanical model of woven fabric and its application to the analysis of buckling under uniaxial tension Part 2: buckling analysis," Int. J. Eng. Sci. vol. 39, pp. 1-13, 2001.

[13] D. Zaccaria, D. Bigoni, G. Noselli, D. Misseroni, "Structures buckling under tensile dead load," P. R. Soc. A vol. 467,pp. 1686-1700, 2011.

[14] K. Markström, B. Storåkers, "Buckling of cracked members under tension," Int. J. Solids Struct. vol. 16, pp. 217-229, 1980.

[15] G.C Sih, Y.D. Lee, "Tensile and compressive buckling of plates weakened by cracks," J. Theor. Appl. Fract. Mech. vol. 6, pp. 129-138, 1986.

[16] D. Shaw, Y.H. Huang, "Buckling behavior of a central cracked thin plate under tension," J. Eng. Fracture Mech. vol. 35, pp. 1019-1027, 1990.

[17] E. Riks, C.C. Rankin, F.A. Brogan, "The buckling behavior of a central crack in a plate under tension," J. Eng. Fract. Mech. vol. 43, pp. 529-547, 1992.

[18] A. Barut, E. Madenci, V.O. Britt, H.J. Starnes, "Buckling of a thin, tension-loaded, composite plate with an inclined crack," Eng. Fract. Mech., vol. 58, pp. 233-248, 1997.

[19] A.N. Guz, M.Sh. Dyshel, "Fracture and buckling of thin panels with edge crack in tension," J. Theor. Appl. Fract. Mech. vol. 36, pp. 57-60, 2001.
[20] M.S. Dyshel, "Stability and fracture of plates with a central and an edge crack under tension," Int. Appl. Mech. vol. 38, pp. 472-476, 2002.

[21] A.N. Guz, M.Sh. Dyshel, Buckling and cracking characteristics of two-layered plate in tension," Theor. Appl. Fract. Mech. vol. 38, pp. 103-107, 2002.

[22] R. Brighenti, "Numerical buckling analysis of compressed or tensioned cracked thin plates," Eng. Struct. vol. 27, pp. 265-276, 2005

[23] R. Brighenti, "Buckling of cracked thin-plates under tension or compression," Thin Wall. Struct. vol. 43, pp. 209-224, 2005.

[24] R. Brighenti, "Buckling sensitivity analysis of cracked thin plates under membrane tension or compression loading," Nucl. Eng. Des. vol. 239, pp. 965-980, 2009.

[25] AA. Rad, D. Panahandeh-Shahraki, "Buckling of cracked functionally graded plates under tension," Thin Wall. Struct. vol. 84, pp. 26-33, 2014.

[26] D. Panahandeh-Shahraki, A.A. Rad, "Buckling of cracked functionally graded plates supported by Pasternak foundation," Int. J. Mech. Sci. vol. 88, pp. 221-231, 2014.

[27] A.E. Seif, M.Z. Kabir, "Experimental study on the fracture capacity and fatigue life reduction of the tensioned cracked plate due to the local buckling," Eng. Fract. Mech. vol. 175, pp. 168-183, 2017.

[28] G.P. Cherepanov, "On the buckling under tension of a membrane containing holes," J. Appl. Math. Mech. vol. 27, pp. 275-286, 1963.

[29] G.C. Backer, Static and dynamic behavior of the tensioned doubly connected plates. School of Aerospace Engineering, Georgia Institute of Technology, Atlanta, GA, 1972.

[30] P.K. Datta, R.L. Carlson, "Buckling and vibration of a thin tensioned sheet with elliptical hole," Exp. Mech. vol. 13, pp. 280-289, 1973.

[31] P.K. Datta, "An experimental study of static and dynamic behaviour of a tensioned sheet with a rectangular opening," Aeronaut. Quart. vol. 257, pp. 257-262, 1976.

[32] P. Larsson, "On buckling of orthotropic stretched plates with circular holes," Compos. Struct. vol. 11, pp. 121134, 1989.

[33] S. Shimizu, S. Yoshida, N. Enomoto, "Buckling of plates with a hole under tension," Thin Wall. Struct. vol. 12, pp. 35-49, 1991.

[34] A. Gilabert, P. Sibillot, D. Sornette, C. Vanneste, D. Maugis, F. Muttin, "Buckling instability and pattern around holes or cracks in thin plates under a tensile load," Europ. J. Mech. - A/Solids, vol. 11, pp. 65-89, 1992.

[35] D.L. Prabhakara, P.K. Datta, "Vibration, Buckling and Parametric Instability Behavior of Plates with Centrally Located Cutouts Subjected to In-Plane Edge Loading (Tension or Compression)," Thin Wall. Struct. vol. 27, pp. 287-310, 1997.

[36] L.R. Kumar, P.K. Datta, D.L. Prabhakara, "Tension buckling and dynamic stability behaviour of laminated composite doubly curved panels subjected to partial edge loading," Compos. Struct. vol. 60, pp. 171-181, 2003.

[37] L.R. Kumar, P.K. Datta, D.L. Prabhakara, "Tension buckling and parametric instability characteristics of 
double curved panels with circular cutout subjected to nonuniform tensile edge loading," Thin Wall. Struct. vol. 42, pp. 947-962, 2004.

[38] S. Shimizu, "Tension buckling of plate having a hole," Thin Wall. Struct. vol. 45, pp. 827-833, 2007.

[39] T. Kremer, H. Schürmann, "Buckling of tension-loaded thin-walled composite plates with cut-outs,", Compos. Sci. Technol. vol. 68, pp. 90-97, 2008.

[40] A. Muc, "Peculiarities in the Material Design of Buckling Resistance for Tensioned Laminated Composite Panels with Elliptical Cut-Outs," Materials vol. 11, 1019, 2018

\section{Creative Commons Attribution License 4.0 (Attribution 4.0 International, CC BY 4.0)}

This article is published under the terms of the Creative Commons Attribution License 4.0

https://creativecommons.org/licenses/by/4.0/deed.en US 